\title{
Protocolos Y AVANCES EN EL ESTUDIO DE RESIDUOS DE pipas arqueológicas de Argentina. Aportes para el ENTENDIMIENTO DE METODOLOGÍAS ACTUALES Y PRÁCTICAS
}

\section{PASADAS}

Verónica S. Lema ${ }^{1}$, Diego Andreoni', Aylen Capparelli', Gabriela Ortiz ${ }^{2}$, Romina Spano 3 , Marcos Quesada ${ }^{4}$ y Flavia Zorzi ${ }^{5}$

\section{* Introducción}

Resumen

Este trabajo presenta el análisis de residuos recuperados en pipas arqueológicas de Argentina, once ejemplares provenientes del noroeste, con un rango temporal del 3600 a $1390 \mathrm{AP}$, y seis históricos de la provincia de Buenos Aires. Se describe el protocolo aplicado para la extracción de muestras, la metodología empleada en laboratorio, los resultados obtenidos a partir de diversas técnicas de procesamiento de los residuos, la colección de referencia de plantas fumitorias y la identificación de micro-restos. Entre estos últimos se ha podido constatar la presencia de Anadenanthera colubrina var. cebil, Trichocline reptans, Nicotiana longiflora, Cestrum spp. y Gossypium spp. Se discuten los resultados obtenidos en relación a las técnicas y métodos aplicados y a ciertos aspectos de las prácticas fumitorias pasadas.

Palabras claves: micro-restos - fumitorios - metodología.

Abstract

This paper presents the residue analysis of archaeological pipes from

Argentina, eleven specimens from the Northwest with a temporal range from 3600 to $1390 \mathrm{BP}$, and six historical ones from the Buenos Aires Province. The paper describes the protocol used in the residue extraction, the laboratory methodology, results obtained from several sample processing techniques, the modern reference collection of smoking plants, and the identification of micro-remains. Among these last ones the presence of Anadenanthera colubrina var. cebil, Trichocline reptans,

Nicotiana longiflora, Cestrum spp. and Gossypium spp. was confirmed. Results are discussed that consider the scope of the techniques and methodology applied, and some aspects of past smoking practices.

Key words: micro-remains - smoking plants - methodology.

Recibido: Abril 2015. Aceptado: Octubre 2015

1 CONICET. Laboratorio de Etnobotánica y Botánica Aplicada-División Arqueología. (FCNyM- UNLP). 60 y 122 s/n CP 1900, La Plata, Buenos Aires, ARGENTINA. Emails: vslema@hotmail.com, andreonidieg@hotmail.com, aylencapparelli@gmail.com
El presente trabajo tiene como objetivo exponer los avances realizados en el análisis arqueobotánico de residuos contenidos en dieciocho pipas arqueológicas de Argentina. La exposición se centra en los siguientes aspectos: 1) Protocolo aplicado para la extracción de muestras de residuos de los artefactos; 2) Metodología para la recuperación de micro-restos a partir de los residuos; 3) Análisis comparativo de la presencia/ausencia de micro-restos en función de los tratamientos aplicados a los residuos; 4) Conformación y caracterización de la colección de referencia; 5) Identificación de micro-restos de los residuos arqueológicos en función de los rasgos diagnósticos de las muestras actuales. A lo largo de las páginas siguientes se hará referencia a los cinco puntos mencionados para, al final del artículo, discutir los resultados y perspectivas con los que contamos.

\section{Las pipas analizadas y los sitios de procedencia}

Huachichocana III (CHIII, Tumbaya, Jujuy; Figura 1-a).

2 CONICET. CREA-UNJU. Otero 262, CP 4600, San Salvador de Jujuy, Jujuy, ARGENTINA. Email: yolatordo@hotmail.com

3 Museo Etnográfico Juan B. Ambrosetti (FFyL-UBA). Moreno 350 (1091) CABA, Buenos Aires, ARGENTINA. Email: romina. spano@gmail.com

4 Centro de Investigaciones y Transferencia de Catamarca (CITCA), CONICET-UNCA. Prado 366, K4700AAP. Escuela de Arqueología, UNCA. Av. Belgrano 300. K4700AAP. San Fernando del Valle de Catamarca, Catamarca, ARGENTINA. Email: mkesada@yahoo.com.ar

5 CONICET. Instituto de Arqueología (FFyL-UBA). Centro de Arqueología Urbana (FADU-UBA). 25 de Mayo 217/221 3er piso, 1002 CABA, Buenos Aires, ARGENTINA. Email: flaviazorzi@gmail.com 
Los artefactos provienen de las intervenciones realizadas por A. Fernández Distel en la década del 70 en este gran abrigo rocoso, situado en una quebrada homónima de acceso a la puna. Entre los contextos descubiertos, se halló el entierro del esqueleto $\mathrm{N}^{\circ} 3$ junto a un profuso acompañamiento mortuorio con objetos y elementos de tierras bajas y altas, entre los que destacan cuatro pipas tubulares de piedra. Los fechados llevados a cabo por Distel, al igual que los más recientes, sitúan este entierro entre 3600-3000 AP. En este trabajo se analizan las pipas 2037 y $2038^{6}$ (muestras U-Z, Tabla 1), las cuales se hallan depositadas en el Instituto Interdisciplinario Tilcara (FFyL-UBA). La primera de estas piezas está confeccionada en andesita, mide $238 \mathrm{~mm}$ de largo, $70 \mathrm{~mm}$ de diámetro y pesa 1850 g; la segunda está elaborada en arenisca roja, mide $227 \mathrm{~mm}$ de largo, $63 \mathrm{~mm}$ de diámetro y pesa 1220 g (Fernández Distel 1980). Tal como lo describe esta última autora, pudo constatarse la presencia de abundantes depósitos de material carbonizado en las paredes internas de ambas piezas. En dicho trabajo se menciona el análisis por cromatografía gaseosa de las pipas de este sitio, sin especificar a cuál de ellas fue aplicado, y se interpreta el resultado como posible indicador de presencia de argemonina, fumaritina, glaucina, hunnemannina y O-methyl-caseadina.

Soria 2 (valle de Santa María, Catamarca; Figura 1-b). El sitio consiste en una unidad habitacional de al menos dos recintos subcuadrangulares adosados, con una cronología de $1940 \pm 80$ AP (LP-1541), donde se habrían desarrollado prácticas como cocción y consumo de alimentos, molienda y elaboración de útiles de piedra (Palamarczuk et al. 2007). Con posterioridad al abandono de la vivienda se llevaron a cabo inhumaciones de infantes. En 2004 y 2010 se encontraron fragmentos de pipas angulares de cerámica con hornillo infundibuliforme, modeladas en pasta fina, con la superficie externa tratada mediante pulido; las mismas fueron aisladas y resguardadas de manipulaciones, tanto en el campo como en gabinete, hasta su posterior estudio. Las muestras G a J (Tabla 1) se extrajeron de dos fragmentos de hornillo, uno de ellos con parte del tubo de la rama vertical, pertenecientes a una pipa de color negro grisáceo, con diseños geométricos incisos y pintados en rojo desvaído, hallada en un pozo de basura situado en el recinto 1. Parte de los contenidos fueron sometidos a cromatografía gaseosa acoplada con espectrometría de masa, los cuales permitieron identificar la presencia de dimetiltriptamina y bufotenina, alcaloides presentes en el género Anadenanthera; en cambio, los análisis dieron resultados negativos para la presencia de nicotina (Rosso y Spano 2005-2006). Con la letra K se identifican los restos contenidos en un fragmento de hornillo hallado en el piso de ocupación del recinto 2, color marrón claro, con diseño ornitomorfo modelado e inciso y aplicación de pintura roja y amarilla desvaída. También se efectuaron análisis químicos sobre los contenidos para la identificación de alcaloides presentes en Anadenanthera, Nicotiana tabacum y Erythroxilum, con resultado negativo (análisis realizados por la Dra. M. Maier, Laboratorio de la Unidad de Microanálisis y Métodos Físicos Aplicados a la Química Orgánica, FCEyN-UBA).

Campo Colorado (SSalLapz) (valle Calchaquí, Salta; Figura 1-c). Asentamiento aldeano formativo compuesto por construcciones de paredes de piedra y barro con montículos asociados. En la década del 60 se excavaron varias estructuras, entre ellas un montículo-basurero que contenía gran cantidad de material cultural, vinculado a un fechado de $1895 \pm 70$ AP (SI-1221) (Tarragó 1980). De esta estructura se recuperaron decenas de fragmentos de pipas de piedra y cerámica; estas últimas se caracterizan por tener la boquilla engrosada, rama horizontal larga y hornillo troncocónico vertical, con dos apoyos cónicos, sin decoración (Tarragó 1980). Las muestras L y LL se encontraban al interior de un fragmento de hornillo de esta clase de pipas, modelado en pasta gruesa, de color rosado, con tratamiento de alisado en la superficie externa; la muestra $\mathrm{M}$ pertenece a un pequeño fragmento de rama horizontal, de similares características. Los fragmentos fueron clasificados y guardados en contenedores plásticos individuales. Una muestra de estos remanentes de uso carbonizados fue estudiada con cromatografía gaseosa acoplada con espectrometría de masa para la identificación de alcaloides de Anadenanthera, N. tabacumy Erythroxilum, sin resultados concluyentes ${ }^{7}$.

6 Números de campo otorgados por A. Fernández Distel.

7 Si bien, en un principio, los estudios químicos practicados sobre los restos contenidos en el hornillo indicaban la presencia de un pico interpretado como correspondiente al alcaloide 5-metoxidimetiltriptamina, presente en el género Anadenanthera (Rosso y Spano 2005-2006), una revisión de los resultados a la luz de nuevos análisis rectificó dicha interpretación (M. Maier, com. pers.). 
Protocolos y aVANCes en el estudio de residuos de pipas arqueológicas de Argentina.

APORTES PARA EL ENTENDIMIENTO DE METODOLOGÍAS ACTUALES Y PRÁCTICAS PASADAS

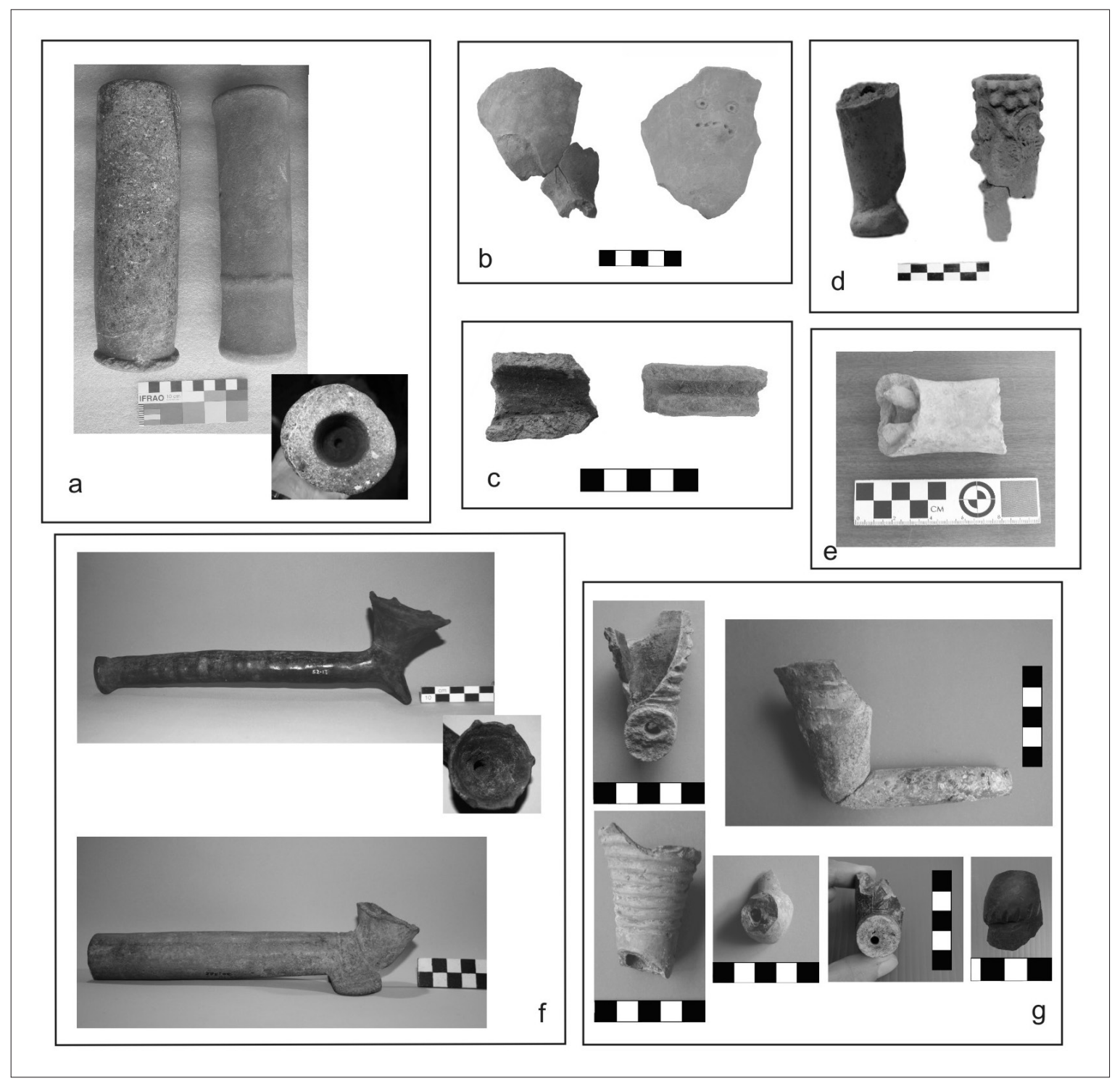

Figura 1. Pipas analizadas. a) Huachichocana III: 2038 (izq.) y 2037 (der.), con detalle del interior de esta última; b) Fragmentos de hornillos de Soria 2 de los cuales se extrajeron las muestras G-J (izq.), y K (der.); c) Fragmentos de tubo de pipas de cerámica de Campo Colorado de los cuales se obtuvieron las muestras L y LL (izq.) y M (der.); d) Fraile Pintado (der.) y Arroyo Colorado (izq.); e) El Taco 19; f) Pipas depositadas en el Museo Etnográfico: Tebenquiche-MEJBA 52-13-(arriba), con detalle del interior del hornillo, y La Candelaria -MEJBA 36-522-(abajo); g) Bolívar 373, de izquierda a derecha y de arriba hacia abajo: pipas 3,4,6,7,8 y 13.

Fraile Pintado y Arroyo Colorado (valle del río San Francisco, Jujuy; Figura 1-d). Los dos fragmentos de pipas provenientes de los sitios Arroyo Colorado y Fraile Pintado fueron recuperados por particulares, ya que ambos sitios arqueológicos se descubrieron fortuitamente y se encuentran en terrenos de propiedad privada. Los sitios se ubican en el fondo de valle, en la cota de $650 \mathrm{msnm}$, muy próximos a cauces de agua subsidiarios del río San
Francisco. En los dos casos se exhumó gran cantidad de material cerámico de estilo San Francisco, así como material lítico, malacológico y restos humanos. No se cuenta con fechados radiocarbónicos debido a las condiciones de hallazgo, pero diferentes sitios localizados en los alrededores cuentan con fechas de comienzos de la era cristiana (2200-1800 AP) (Ortiz y Nieva 2014). El ejemplar de Fraile Pintado (muestras P-RR, Tabla 1) corresponde a 
un fragmento de pipa de cocción reductora conformado por hornillo tubular y codo de articulación con rama horizontal. Presenta un acabado de superficie bruñido y dos mamelones en la base, entre los cuales se aprecia un orificio. La mayor parte de las pipas de estilo San Francisco tienen este orifico basal, que sirve para el control de la combustión al permitir el ingreso de oxígeno debido a la estrechez del canal interno, pudiendo haber sido también utilizado para la limpieza de la rama horizontal. La pipa de Arroyo Colorado (muestras S y T, Tabla 1) corresponde a un fragmento de hornillo de cocción oxidante. Presenta decoración modelada antropomorfa, con la aplicación al pastillaje de pequeños mamelones alrededor del orificio de abertura del hornillo. En ambos ejemplares se realizaron análisis para la detección de ácidos grasos constitutivos, habiéndose detectado entre otros el ácido erúcico. Este último se encuentra en las semillas de cebil sobre la base de la extracción realizada en semillas de recolección actuales (Ortiz y Heit 2011).

El Taco 19 (ET 19, serranías de El Alto, Ancasti, Catamarca; Figura 1-e). Fragmento de pipa recuperada de la excavación de una vivienda arqueológica que integra un conjunto aldeano disperso (Quesada et al. 2012). Si bien la vivienda se ubica en el sector cumbral y en un ámbito de pastizales, a pocos kilómetros al este y en una franja vegetacional más baja se encuentran vastos bosques de cebil. Asimismo, en la actualidad es posible observar, principalmente en espacios perturbados próximos a las viviendas actuales, la presencia de tabaquillo (Nicotiana spp.). El ejemplar analizado corresponde al codo y parte de la rama vertical (muestras AA y AB de la Tabla 1). Se hallaba incluido en un estrato inmediatamente subyacente al derrumbe de los muros, por lo cual podría corresponder a los últimos momentos de ocupación de la vivienda. Se encontraba en asociación contextual con cerámicas pintadas y grabadas, entre ellas Aguada Portezuelo y Ambato Negro Grabado. Una muestra de hueso incluida en este estrato fue datada en $1390 \pm 70 \mathrm{AP}$ (LP2583), siendo el rango temporal correspondiente tras la calibración con un sigma de 643 a 772 AD (Quesada et al. 2012).

Tebenquiche (Salar de Antofalla, puna catamarqueña; Figura 1-f). Pipa recuperada en el marco de las investigaciones de P. Krapovickas en los años 50 y depositada en el Museo etnográfico "J. B. Ambrosetti" ( $\mathrm{N}^{\circ}$ de inventario
MEJBA 20526 [52-13]). Se trata de un ejemplar de tipo angular de alfarería pardonegruzca pulida, elaborado con pasta intermedia, con hornillo infundibuliforme corto que nace directamente de la rama horizontal, boquilla engrosada y dos patas tronocónicas; el hornillo exhibe decoración incisa geométrica y apliques modelados en el borde, además de pintura roja postcocción. La pieza fue hallada en una cámara funeraria huaqueada, de cronología temprana (Krapovickas 1955). Al momento de practicarse la extracción de la muestra $\mathrm{N}$, se encontraba en exhibición.

La Candelaria (La Candelaria, Yungas salteñas; Figura 1-f). Se trata también de una pieza procedente de las colecciones del Museo etnográfico (MEJBA 36-522) hallada en el marco de las expediciones arqueológicas de $\mathrm{R}$. Schreiter de los años 30. Pipa angular de cerámica, confeccionada en pasta intermedia, pulida, de color marrón, hornillo infundibuliforme con diseños geométricos incisos en su base y dos patas de apoyo de sección rectangular (muestras Ñ y O). Por el registro fotográfico de la expedición, junto con los documentos relacionados a la adquisición del lote de piezas ofrecidas por Schreiter, se infiere que la pipa procede de un contexto funerario $y$, por su morfología y estilo, consideramos que es una pieza de cronología formativa.

Bolivar 373 (Figura 1-g). El sitio se ubica en el centro histórico de la ciudad de Buenos Aires y cuenta con numerosos depósitos y estructuras que datan de los siglos XVII, XVIII y XIX. Entre los años 2005 y 2011 se recuperaron gran número de pipas de diverso tipo, que abarcan todo el lapso mencionado. En este trabajo se presenta el análisis de seis pipas modeladas en terracota, (muestras A-F, Tabla 1). Las pipas 3 y 7 provienen de un pozo de basura junto a un conjunto de restos (óseos, cerámica hispanoindígena y utilitaria de tradición española) cuya cronología es de primera mitad del siglo XVII. Las pipas 4,6 y 8 poseen igual cronología y provienen de un pozo circular excavado en la tosca, cuyas características y elementos recuperados indican usuarios de posición social elevada. La pipa 13 fue recuperada en un pozo de letrina que contenía un depósito de materiales domésticos datados hacia la segunda mitad del siglo XVIII. En todos los casos se recuperaron fragmentos cuyo remontaje - total o parcial - permitió su caracterización. La pieza 3 es una pipa angular con tubo cilíndrico y hornillo cónico, pasta de 
superficie color anaranjado claro. Posee decoración de líneas incisas, paralelas, que rodean toda la circunferencia del hornillo, entre las cuales hay restos de pintura roja; las paredes internas del hornillo se hallan ennegrecidas y tiznadas. La pipa 4 es del mismo tipo, sin decoración y con parte de la superficie interna del hornillo ennegrecida. La pipa 6 es un hornillo de pipa angular, muy similar a la pieza 3, aunque sin restos de pintura. La pieza 7 corresponde a la base de un hornillo de una pipa compuesta, a la que seguramente se le adosaba un hueso de ave o una cañita a modo de tubo. Las superficies fueron alisadas y bañadas en un engobe anaranjado, ennegrecido en la superficie interna debido al uso. La pieza 8 es también similar a la 3, el conducto de circulación del humo está ligeramente descentrado. La decoración del hornillo consiste en una banda vertical formada por diseños triangulares grabados con líneas incisas. La pieza 13 es un fragmento de hornillo globular que exhibe una serie de incisiones unguiculares verticales (Zorzi y Davey 2011).

\section{Protocolo de extracción de residuos de las pipas}

El número y la diversidad de pipas analizadas (algunas representadas por fragmentos y otras como piezas enteras) nos permitió contar con un conjunto variado de tipos de residuos. En cuanto a su aspecto se pudieron diferenciar aquellos en forma de costras más o menos consolidadas (pipas CHIII, La Candelaria, Tebenquiche, Bolívar 373 pipa 3), y en forma de tizne. Asimismo, existieron diferencias en cuanto a la visibilidad y accesibilidad a estos residuos, las que tuvieron relación con la morfología y estado de conservación de las pipas, fundamentalmente el tamaño del hornillo y la fragmentación (en sentido transversal o longitudinal) de los tubos - o ramas-verticales u horizontales.

La extracción de muestras se realizó con instrumental de plástico duro descartable, o bien metálico en el caso de adherencias muy consolidadas. Este último fue esterilizado exponiéndolo al fuego directo hasta alcanzar el rojo vivo, a fin de destruir la mayor cantidad posible de restos orgánicos. Una vez enfriado, se lavó el instrumental con agua destilada para arrastrar todo residuo remanente y se dejó secar. Esto se realizó cada vez que hubo que usar el instrumento para obtener una nueva muestra, a fin de evitar contaminación cruzada. La extracción de muestras se hizo siempre en ambientes cerrados, con superficies limpias y las manos del operario también limpias o con guantes sintéticos libres de fécula. En el caso de pipas con sedimento de relleno por sobre el residuo de combustión, se recuperó el mismo como muestra control (Planella et al. 2012; Belmar et al. 2015). Primeramente se limpió la superficie con un pincel nuevo de cerdas sintéticas suaves. Luego se raspó con suavidad el sedimento - empleando un elemento metálico esterilizado o plástico descartable - hasta retirarlo y guardarlo en un recipiente nuevo. En el caso de presencia de raicillas, estas se retiraron con pinzas metálicas esterilizadas sin romperlas. Una vez guardada la muestra control, se procedió a retirar parte del residuo de combustión raspando delicadamente con el instrumental antes descrito, y a depositarlo en otro recipiente nuevo para su posterior estudio. Sólo en los casos necesarios se retiró todo el residuo, a fin de no generar, durante el proceso de extracción, marcas en los artefactos a pesar de raspar siempre con suavidad (Belmar et al. 2015).

En el caso particular de la pipa de El Taco 19, se extrajo primero - con elementos metálicos esterilizados a fuego- el sedimento que rellenaba el fragmento de rama vertical, el cual no fue objeto de análisis. Luego se raspó - con otro punzón metálico esterilizado- el sedimento de relleno próximo a las paredes internas del tubo y codo, el cual se guardó como muestra control. Luego, con una pipeta (usando tips descartables) se volcó agua destilada en la superficie a muestrear, se dejó reposar la misma por unos pocos segundos, se absorbió el agua de la superficie y se guardó la muestra en recipientes nuevos. Esto se realizó con el fin de testear la eficacia de este método de extracción con agua, respecto a la extracción en seco realizada en el resto de los casos.

\section{Metodología para la recuperación de micro-restos a partir de los residuos}

Estudios recientes de contenidos de pipas arqueológicas han optado por un análisis directo del residuo de combustión a fin de obtener el mayor número posible de micro-restos y reducir potenciales alteraciones, daños o destrucción de material por tratamientos considerados agresivos. En estos casos se aplicó el método de extracción directa de residuos por raspado, siguiendo el protocolo para análisis múltiple de microfósiles mediante flotación en líquido pesado (Ioduro de Zinc) (Planella et 
al. 2012; Quiroz et al. 2012; Belmar et al. 2015). En cambio en nuestro caso, teniendo en cuenta los resultados positivos obtenidos previamente por el equipo (Capparelli et al. 2006), la escasa visibilidad obtenida al tratarse de material carbonizado y la presencia ocasional de costras muy difíciles de deshacer, optamos por aplicar diversos tratamientos químicos. Principalmente se aplicaron reactivos que decoloraron los residuos, permitiendo su observación al microscopio óptico: ácido láctico, peróxido de hidrógeno (100 vol.) e hipoclorito de sodio. En dos muestras se aplicó acetona como solvente de resinas, aunque no posee efecto decolorante. En todos los casos se experimentó variando la concentración y/o el tiempo de exposición a los reactivos (Tabla 1), tomando en consideración que el ácido láctico posee una acción lenta y no destructiva, el hipoclorito de sodio lo contrario (acción rápida y destructiva) y el peróxido de hidrógeno una acción intermedia respecto de ambos.

Luego del tratamiento las muestras fueron montadas en portaobjetos, empleando medios con distinta perdurabilidad: gelatina-glicerina o agua-glicerol al 50\%, salvo aquellas muestras tratadas con ácido láctico, el cual actúa también como un buen medio de montaje. En algunos casos, se seleccionaron pequeños fragmentos de costras, los cuales se extrajeron y montaron empleando una aguja esterilizada a fuego. Los mismos fueron parcialmente fragmentados con dicho instrumento sobre el portaobjetos. En todos los casos se selló el área entre cubre y portaobjetos con esmalte de uñas. Para el montaje de las muestras se emplearon materiales nuevos. Las manos del operario fueron lavadas antes del tratamiento de cada muestra, al igual que las superficies de trabajo. El espacio de montaje y observación se mantuvo cerrado a fin de evitar las corrientes de aire y la subsecuente posibilidad de contaminación. Asimismo, se espació en el tiempo el procesamiento de materiales de referencia y el de residuos arqueológicos para evitar potencial contaminación cruzada. Las muestras fueron observadas al microscopio óptico a 200X y 500X, bajo luz normal y polarizada.

Residuos de dos pipas (Pipa 3 de Bolívar 373 y pipa 2038 de CHIII) fueron observados al microscopio electrónico de barrido (MEB). Las muestras fueron tratadas en primer lugar con ácido láctico al 100\% por 15 días, luego se retiró este reactivo y se colocaron en alcohol al 50\% durante 15 minutos, tiempo tras el cual — sólo en el caso de Bolívar 373 - se seleccionó una costra y el resto del sobrenadante fue observado empleando microscopía óptica (Tabla 1, muestra A). Esta costra y el total de la adherencia carbonosa de CHIII fueron colocadas en alcohol 96\% durante 15 minutos más y luego se dejaron secar por un día y medio. Se usaron para su manipulación pinzas esterilizadas.

\begin{tabular}{|c|c|c|c|c|c|c|c|c|c|c|c|}
\hline SITIO & MUESTRA & REACTIVO & $\begin{array}{c}\text { TIEMPO } \\
\text { HASTAEL } \\
\text { MONTAJE }\end{array}$ & \begin{tabular}{|c|} 
TIEMPO \\
\\
ENTRE \\
MONTAJE Y \\
OBSERVACIÓN \\
\end{tabular} & ALMIDONES & $\begin{array}{l}\text { FIBRAS (de } \\
\text { superficie, } \\
\text { liberianas, } \\
\text { foliares) }\end{array}$ & ESCLEREIDAS & TEJIDOS & $\begin{array}{l}\text { TRICOMAS } \\
\text { O PARTES } \\
\text { (no } \\
\text { silicificados) }\end{array}$ & \begin{tabular}{|c} 
CELULAS \\
AISLADAS
\end{tabular} & $\begin{array}{l}\text { ELEMENTOS } \\
\text { DE } \\
\text { CONDUCCIÓN } \\
\text { (vasos, haces } \\
\text { vasculares) } \\
\end{array}$ \\
\hline \multirow{6}{*}{ Bolivar 373} & $\begin{array}{c}\text { A } \\
\text { Pipa } 3\end{array}$ & A.L. & $\begin{array}{c}15 \text { dias } \\
+ \\
\text { alcohol }(50 \%) \\
15 \text { min. }\end{array}$ & - & $\mathrm{x}$ & & $\mathrm{x}$ & $\mathrm{x}$ & & & $\mathrm{x}$ \\
\hline & $\begin{array}{c}\text { B } \\
\text { Pipa } 4 \\
\end{array}$ & H.S. $(50 \%)$ & 25 minutos & - & & $\mathrm{x}$ & & $\mathrm{x}$ & $\mathrm{x}$ & $\mathrm{x}$ & $\mathrm{x}$ \\
\hline & $\begin{array}{c}\text { C } \\
\text { Pipa } 6\end{array}$ & A.L. & $3 y^{1 / 2}$ meses & - & $\mathrm{x}$ & & & & & $\mathrm{x}$ & \\
\hline & $\begin{array}{c}\text { D } \\
\text { Pipa } 7\end{array}$ & P.H. $(100 \%)$ & 24 hrs. & - & $\mathrm{x}$ & $\mathrm{x}$ & & & $\mathrm{x}(?)$ & & \\
\hline & $\begin{array}{c}\text { E } \\
\text { Pipa } 8 \\
\end{array}$ & P.H $(100 \%)$ & $48 \mathrm{hrs.}$ & - & & & & & & $\mathrm{x}$ & $\mathrm{x}$ \\
\hline & $\begin{array}{c}\text { F } \\
\text { Pipa } 13\end{array}$ & - & - & - & & & & & & $\mathrm{x}$ & $\mathrm{x}$ \\
\hline
\end{tabular}


Protocolos y aVANCes en el estudio de residuos de pipas arqueológicas de Argentina.

APORTES PARA EL ENTENDIMIENTO DE METODOLOGÍAS ACTUALES Y PRÁCTICAS PASADAS

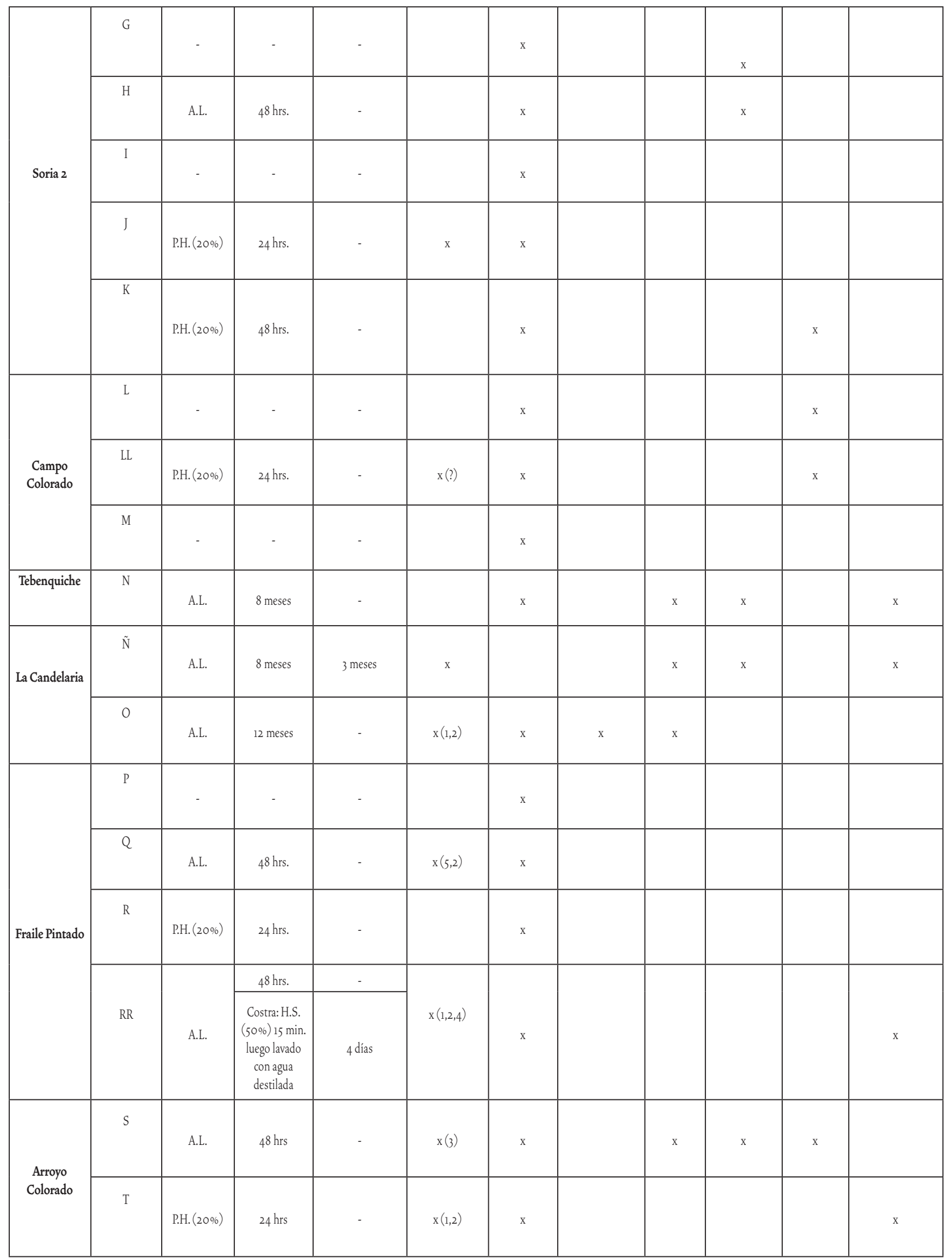




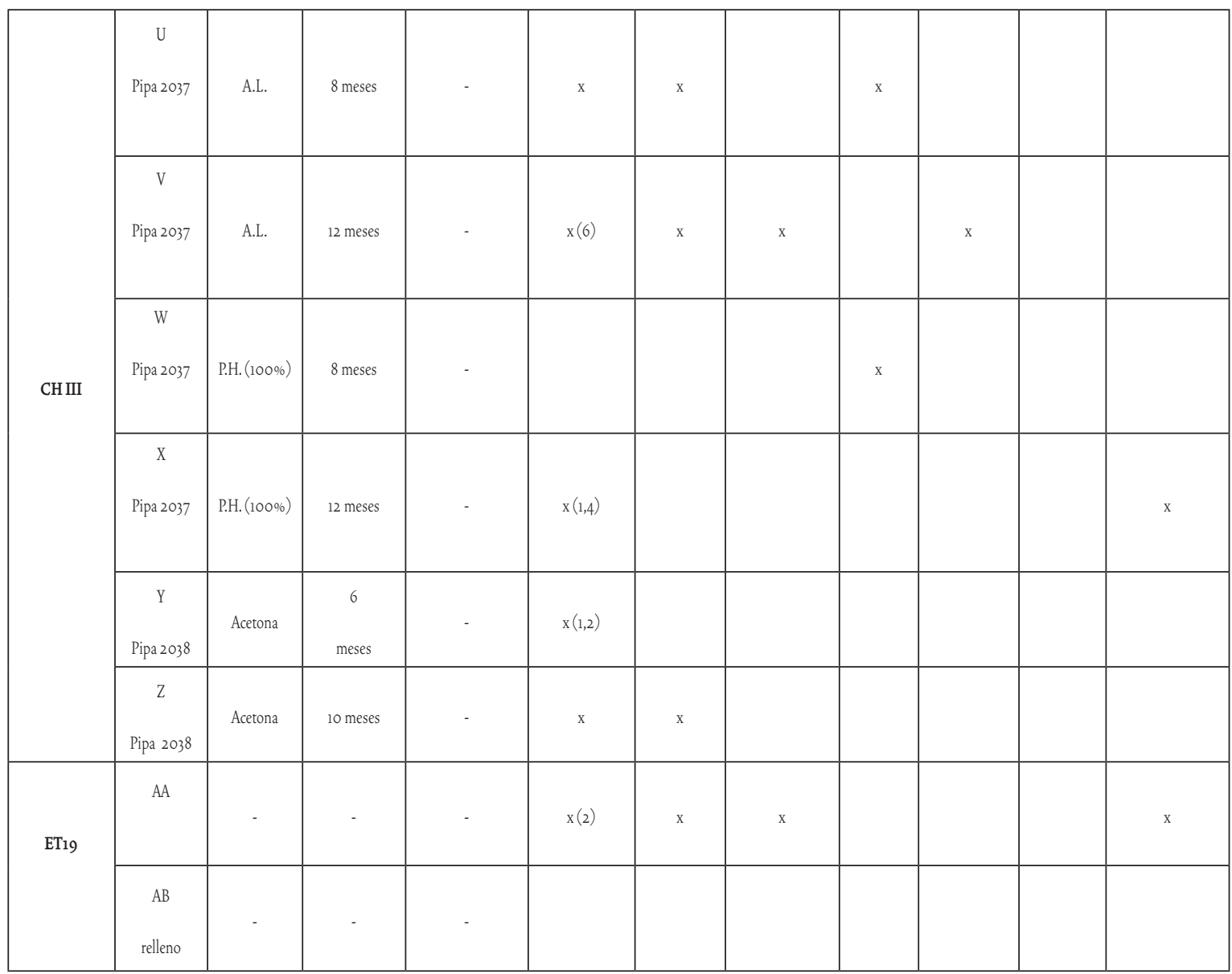

Referencias: $\mathrm{A}-\mathrm{AB}=$ rótulo de las muestras. "?" = asignaciones dudosas. A.L. =ácido láctico 100\%, H.S.=hipoclorito de sodio., P.H=peróxido de hidrógeno 100 vol. $(1-6)=$ tipos de granos de almidón identificados: $1=$ Anadenanthera colubrina var. cebil Tipo 1; $2=$ Nicotiana aff. longiflora Tipo C o Trichocline reptans Tipo II; 3 = Nicotiana aff. longiflora Tipo F; $4=$ Nicotiana aff.longiflora Tipo A; 5 = Anadenanthera colubrina var. cebil Tipo 3; 6= Trichocline reptans Tipo I.

Tabla 1. Presencia/ausencia de tipos de micro-restos vegetales recuperados de los residuos de pipas aquí tratadas, de acuerdo a las diferentes clases de tratamientos aplicados a los mismos.

\section{Análisis comparativo de la recuperación de micro- restos en función de los tratamientos aplicados a los residuos}

En este apartado nos interesa analizar los tratamientos aplicados a los residuos de las pipas en función de la recuperación diferencial de los tipos de micro-restos listados en la Tabla 1. Allí se indican datos de presencia/ausencia y no cantidades absolutas, ya que nos interesa evaluar si los tratamientos se pueden asociar o no a la recuperación de parte o a la destrucción total de diferentes elementos tras su aplicación. En el caso de los elementos conserva- dos, cabe la posibilidad de que haya habido una pérdida porcentual de material luego del tratamiento. Como no hemos analizado las muestras con fines de cuantificación ${ }^{8}$, no estamos en condiciones de evaluar este aspecto; por lo tanto, al hablar de conservación o pérdida diferencial de material, lo haremos sólo en relación a la riqueza en tipos de micro-restos.

8 Un estudio de corte cuantitativo debe incluir la estandarización de cantidades de sedimento o campos a observar, o bien unificar los tiempos de observación, a fin de evitar la sobre o subponderación de elementos. 
Analizando la Tabla i puede verse que el aumento en la concentración (p.e., $20 \%$ versus 100\%) y/o tiempo de exposición (24 horas a 12 meses) de algunos reactivos (p.e., peróxido de hidrogeno, ácido láctico o acetona) no se asocia con una disminución progresiva de riqueza en tipos de material. Tampoco se asocia a una no representación de almidones. A su vez, la ausencia de tratamiento no se correlaciona con una mayor recuperación de tipos de micro-restos (ver por ejemplo muestras L y LL, que corresponden a un mismo residuo arqueológico), por el contrario, en estos casos se observó la presencia de agregados oscuros de material carbonizado, que dificultó el reconocimiento de estructuras vegetales. Así, de las 31 muestras presentadas en la Tabla 1, ocho no tuvieron tratamiento, y de las mismas se recuperaron más frecuentemente uno o dos tipos de micro-restos, excepcionalmente cinco (sólo en este último caso, almidones); en cambio, de las 23 muestras con tratamiento químico, se recuperaron más usualmente dos, tres, cinco o más tipos de micro-restos, incluidos esclereidas y fibras, que fueron los tipos más frecuentes en las muestras que no tuvieron tratamiento. Es por ello que consideramos que el uso de reactivos no parece haber producido destrucción de tipos de micro-restos en las muestras. Por citar algunos ejemplos, las muestras $\mathrm{N}$ a $\mathrm{O}$ de colecciones de pipas del Museo etnográfico que tenían abundante material combustionado en su interior - tanto adherido fuertemente como suelto o desgranado- evidencian que una exposición prolongada al ácido láctico en su concentración mayor no atentaría contra la conservación o integridad de restos vegetales; por el contario, permitió recuperar una variedad de tipos diferentes (p.e., cuatro en la muestra O). El caso de las muestras de Fraile Pintado ( $\mathrm{P}$ a RR) nos permite comparar los resultados obtenidos de un mismo residuo, previa y posteriormente a la aplicación de diversos reactivos. En esta oportunidad se pudo ver que tanto el uso de reactivos de acción lenta en concentración máxima y por un tiempo moderado (ácido láctico, 100\%, 48 horas), moderadamente rápidos en concentraciones bajas y por menor tiempo (peróxido de hidrógeno, 20\%, 24 horas.), como los de acción rápida a concentración baja y muy poco tiempo (hipoclorito de sodio, $50 \%, 15$ minutos), no destruirían por completo el material orgánico. Incluso en el caso de la muestra RR con doble tratamiento, se recuperaron tanto almidones aislados como en agregados en buen estado de preservación.
En el caso de la pipa 2037 del sitio CHIII (muestras U a X), la misma poseía una concentración carbonosa notablemente abundante en su interior (Figura 1-a), muy compacta y endurecida, por lo cual se sometió a un tratamiento prolongado de varios meses con reactivos de acción lenta y moderada en sus máximas concentraciones. El tratamiento permitió la recuperación de micro-restos, incluso se observó una correlación positiva entre el tiempo de exposición y la riqueza en tipos de elementos vegetales encontrados, parte de los cuales se mostraron sin daño. La pipa 2038 de este mismo sitio (muestras Y y Z) también poseía adherencias muy compactas y endurecidas. En este caso, y por sugerencia del Dr. A. Chevalier, se probó el uso de acetona como solvente a fin de desagregar las costras obtenidas tras el raspado. Se procedió a colocar un pequeño bloque carbonoso $(3 \times 3 \mathrm{~mm}$ aproximadamente) en acetona al 100\% por seis meses (muestra Y), tras los cuales el bloque estuvo desagregado. Se lograron recuperar numerosos almidones, algunos en buen estado y otros con fisuras. Dado que la acetona actúa solo como diluyente (y no, por ejemplo, como decolorante) resultó llamativo que no se requiriera de otro tratamiento para visibilizar los residuos contenidos en el interior de la concreción. La misma muestra, montada meses después (Z), registró la presencia de fibras y almidones sin daños, por lo cual se puede decir, por un lado, que las fisuras observadas en los almidones de la muestra $Y$ no necesariamente fueron producto de la aplicación de acetona, $y$, por el otro, que esta no impidió la recuperación de fibras. Si este producto interfiere o no con la recuperación de otras estructuras orgánicas es algo que deberá ser corroborado mediante el estudio de un mayor número de muestras a futuro. Por último, en el caso de la pipa recuperada en el sitio El Taco 19 se comprobó que, para el caso de residuos que no son concreciones, sino tizne, la extracción mediante pipeteado con agua destilada en lugar del raspado practicado en los casos previos, permitió, luego del montaje directo, la recuperación y visibilidad de varios tipos de restos (muestra AA). La ausencia de los mismos en el sedimento que estaba rellenando el tubo (muestra $\mathrm{AB}$ ) nos lleva a proponer el vínculo entre los residuos de la muestra AA y la acción de fumar en el pasado.

En cuanto a la recuperación de granos de almidón, de las dieciséis combinatorias entre reactivos, tiempos de exposición y tiempos hasta su observación, que se detallan en la Tabla 1, se registró la presencia de los mismos en 
todos los casos donde se aplicó ácido láctico o acetona. En el caso del peróxido de hidrógeno, si bien hay muestras donde no se recuperaron almidones tras la aplicación del mismo al $20 \%$ y al $100 \%$ por 48 horas, la presencia de granos en la muestra $\mathrm{X}$ - expuesta a este reactivo al $100 \%$ por doce meses - sugiere que la ausencia de estos compuestos subcelulares en muestras expuestas por menos tiempo y/o menos concentración no se debería a la acción particular de este reactivo químico. Lo mismo puede decirse para el caso de aplicación de hipoclorito de sodio (50\%), que registra muestras donde los almidones aún están presentes luego de cuatro días de acción desde el montaje a la observación' (muestra RR). Es por ello que proponemos que estos tratamientos no destruyen totalmente los granos, aunque no sabemos en qué medida pueden limitar las cantidades recuperadas de los mismos. A su vez, en todos los casos donde se encontraron granos de almidón, se hallaron de manera conjunta ejemplares con y sin daño, sin que se observara correlación entre las combinatorias reactivo/tiempo de exposición aplicadas y un tipo particular de alteración de los granos (ver más abajo).

Los daños más comunes reportados para almidones recuperados de residuos en pipas sin tratamiento químico son: pérdida de birrefringencia, alteración del hilio y cicatrices, y fueron vinculados al desecamiento, molienda, tostado y carbonización, etapas de procesamiento y consumo propias de un fumitorio (Planella et al. 2012). La desecación, en tanto aplicación de calor en seco, puede ocasionar pérdida parcial de birrefringencia y fisuras proyectadas desde el hilum y cavidades en el grano (Radley 1968; Babot 2007, 2009; Henry et al. 2009). La combustión en seco que se produce del material vegetal fumado - previamente desecado- ocasiona, en los granos de almidón, el proceso denominado dextrinización (Zarillo et al. 2008). El calor seco e intenso hidroliza las moléculas del almidón en dextrinas (moléculas de almidón más

9 Si bien el blanqueamiento de almidón puede darse mediante el uso - bajo ciertas condiciones de temperatura y $\mathrm{pH}$ - de hipoclorito de sodio como agente oxidante, no estamos en condiciones de afirmar que dicha reacción se dio en las muestras que procesamos. De todos modos, si este fuese el caso, la oxidación no altera la estructura cristalina ni la morfología de los almidones (Rivas-González et al. 2008; García Tejeda et al. 2011). cortas) y maltosa (Wandsnider 1997). Al no intervenir el agua, no se produce hinchamiento ni gelificación de los granos; a medida que se aplica calor (entre 200 y $220^{\circ} \mathrm{C}$ ) los granos primero pierden birrefringencia, y luego, totalmente su estructura cristalina (Takahashi et al. 1982), aunque conservan su morfología externa general. En los casos tratados por nosotros, las alteraciones observadas en los granos fueron: disminución de la birrefringencia y fisuras. Dadas las consideraciones anteriores, al hecho de que los granos con daño en nuestro caso se recuperaron paralelamente a granos sin daño alguno, y a que no hubo correspondencia evidente entre la existencia de daño y los tratamientos químicos aplicados, no podemos vincular hasta el momento las alteraciones que observamos en los granos de almidón exclusivamente a la actividad fumitoria, o a los reactivos que aplicamos, ni a ambos factores en su conjunto. Consideramos que se deben realizar experimentaciones a futuro para estudiar este aspecto.

Finalmente, las observaciones al MEB no evidenciaron estructuras vegetales reconocibles. Esto indica que el montaje de costras sin un intenso tratamiento químico previo (como en Capparelli et al. 2006), no ofrece resultados satisfactorios en este tipo de microscopio.

\section{Colección de referencia para el análisis de residuos en pipas}

La confección de una colección de referencia de plantas con la cual contrastar los residuos hallados en pipas debe contemplar una gran diversidad taxonómica y de partes útiles. Además de plantas con efectos psicoactivos, deben considerarse aquellas empleadas como aromatizantes, atemperantes, sucedáneas y potenciadoras de las primeras (Andreoni y Capparelli 2007). Asimismo, las tareas de limpieza de las pipas, al igual que el empleo de filtros, lleva a considerar otro conjunto de plantas; también los análisis químicos arrojan una lista de alcaloides que pueden orientar la búsqueda en dirección a taxa que los contengan (Andreoni 2010).

En la colección conformada para el presente trabajo, se analizaron distintas partes útiles de siete especies nativas con propiedades psicoactivas: flores y hojas de Cestrum parqui L'Hér (Liscovsky y Cosa 2005; Quiroz et al. 2012; Albornoz 2015), hojas, flores y semilla de Datura inoxia Mill. (Chase Sardi 1977; Carpano et al. 1990; Quiroz et al. 
2012; Albornoz 2015), hojas y flores de Brugmansia arborea L. (Chase Sardi 1977; Carpano et al. 1990; Albornoz 2015), raíces de Nicotiana longiflora Cav., hojas y flores de N. tabacum L. (Goodspeed 1954; Korstanje y Babot 2005; Scarpa y Rosso 2011; Albornoz 2015; Quiroz et al. 2015), rizomas de Trichocline reptans (Wedd.) Hieron (Zardini 1976-1977), hojas de Psychotria carthagenensis Jacq. y folíolos y semillas de Anadenanthera colubrina (Vell.) Brenan var. cebil (Griseb.) Altschul (Pochettino et al. 1999; Korstanje y Babot 2005; Pagan Jiménez y Carlson 2014). En este último caso, tres semillas enteras fueron tostadas y molidas a fin de reproducir los modos tradicionales que se informan para su procesamiento (Andreoni y Capparelli 2007; Pagan Jiménez y Carlson 2014). El residuo obtenido se decoloró con hipoclorito de sodio al $50 \%$ y se efectuaron tres observaciones a los 10, 20 y 30 minutos. Una porción de la muestra anterior fue colocada en un tubo de ensayo nuevo y expuesta a la llama directa de un mechero Bunsen hasta lograr su combustión. Luego se agregó al tubo peróxido de hidrógeno (100 vol.) al 30\% por tres días hasta su análisis al microscopio. A la anterior, se suma la confección de una colección de referencia de fibras de superficie y foliares de Gossypium barbadense y bromeliáceas nativas (géneros Dickia y Bromelia).

Teniendo en cuenta los elementos que hemos hallado en las pipas (Tabla 1), presentamos los siguientes rasgos diagnósticos para los mismos, considerando lo observado por nosotros en la colección de referencia y la información contenida en la bibliografía antes citada:

Esclereidas. Las macroesclereidas de las cubiertas seminales del cebil (Figura 2-1) resultaron diagnósticas dentro del conjunto de plantas de la colección de referencia y han demostrado su utilidad en el análisis de contenedores vinculados al complejo del rapé (Pochettino et al. 1999). El procesamiento de las semillas de cebil evidenció que macroesclereidas y esclereidas sobreviven al tostado, molienda y combustión. Las esclereidas de las testas de semillas de $D$. inoxia con engrosamientos interrumpidos en la pared, resultaron también exclusivas de este taxón (Figura 2-2).

Elementos de conducción. Haces vasculares con engrosamientos espiralados están presentes en hojas de todos los taxa reportados, además de ser abundantes en gran número de plantas. En lo que refiere a los elementos de vasos, los observados en T. reptans, con contorno semirectangular y paredes con engrosamiento escalariforme, que poseen aspecto arrosariado en los contornos de la célula, fueron exclusivos de esta especie (Figura 2-3).

Cristales. Desde lo cualitativo, sólo los rafidios en hojas de P. carthaginensis (Figura 2-4) fueron diagnósticos. Cristales cúbicos y romboidales se hallan en tricomas glandulares de hoja de tabaco (Figura 2-6), en hoja de D. inoxia (Figura 2-7) y en semilla de cebil (Figura 2-8). En estas dos últimas - al igual que en hoja de B. arbórea - se hallaron drusas. Goodspeed (1954) menciona la presencia de drusas en cabezuelas glandulares de hojas de tabaco, pero no pudimos detectarlas. La experimentación en el caso de semillas de cebil indica que las drusas no parecen sobrevivir al tostado, molienda y combustión.

Tricomas. El carácter diagnóstico de los tricomas, considerando las condiciones de conservación en residuos arqueológicos, es altamente dependiente del grado de integridad con el que se los recupere. No obstante, aun cuando posean un estado óptimo de preservación, puede señalarse que, en lo que refiere a tricomas eglandulares, los uniseriados multicelulares se hallan en varias especies: C. parqui (hoja), Nicotiana spp. (hoja y flor), $D$. inoxia (hoja) y B. arbórea (hoja); en estos dos últimos casos, pueden ser verrugosos. A nivel cualitativo, salvo por este último rasgo, este tipo de tricomas es poco diagnóstico. Los unicelulare - que poseen mejores chances de preservación - se encuentran en $C$. parqui (flor) y $P$. carthaginensis (hoja), también en los folíolos del cebil, aunque en este último caso tienen paredes engrosadas y son de tipo aguijón (Figura 2-9). Los estrellados se hallan sólo en $P$. carthaginensis (Figura 2-10) y los ramificados en Cestrum spp. (hoja y flor) y Nicotiana spp (hoja). Los tricomas glandulares tienen menos probabilidades de ser recuperados con sus cabezuelas, teniendo en cuenta que esta estructura es particularmente frágil dada su funcionalidad, por lo cual la ausencia de ésta puede llevar a interpretarlos, en el caso de aquellos pedicelados, como tricomas eglandulares uniseriados rotos, o bien, como células aisladas en el caso de pies unicelulares. Tricomas de pie unicelular y cabezuela unicelular se hallan en Cestrum (hoja) y Nicotiana (hoja y flor), de pie unicelular y cabezuela pluricelular en hojas de D. inoxia (Figura 2-11) y Brugmansia (Figura 2-12). Los pedicelados pluri- 


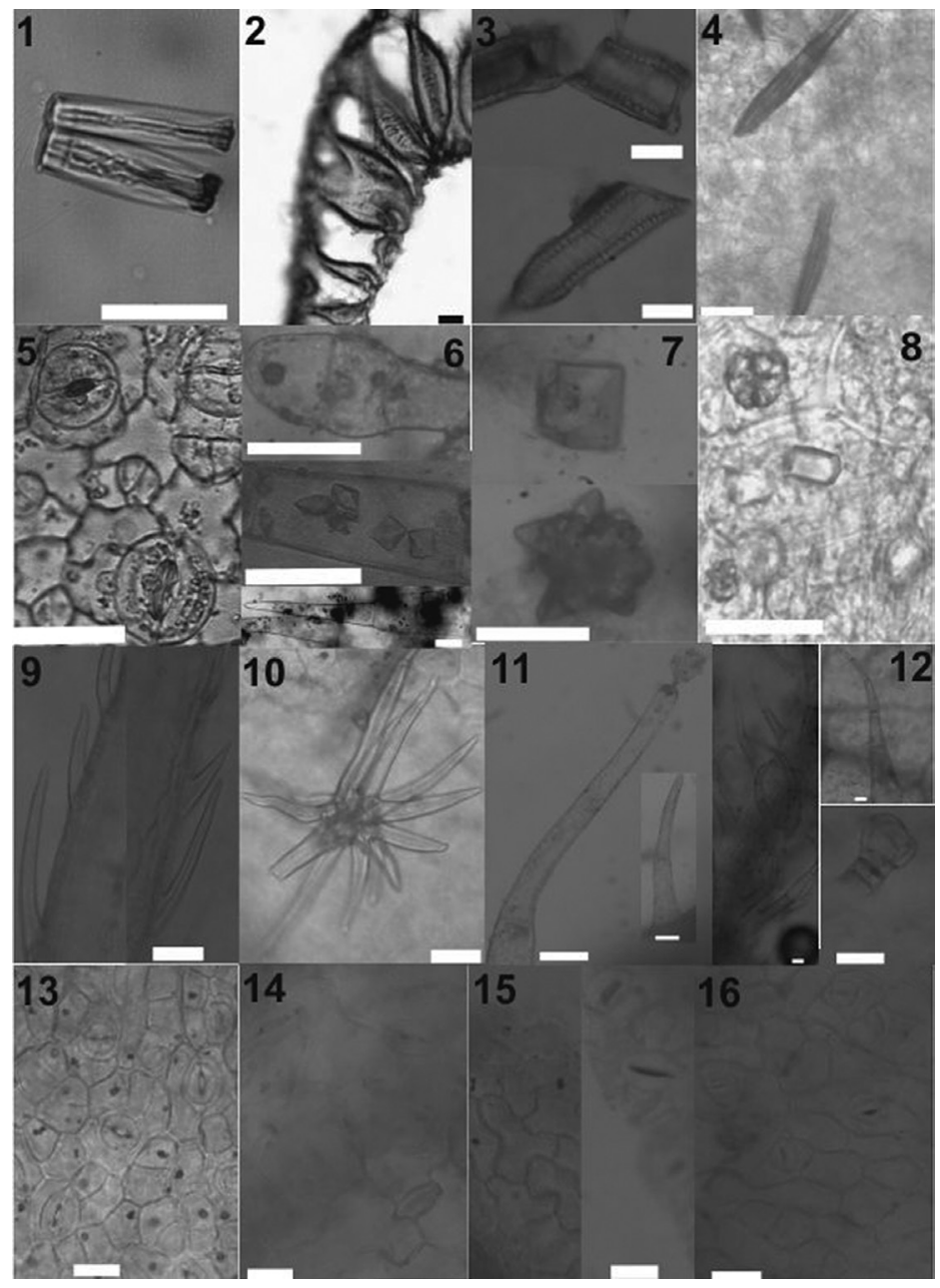

Figura 2. Colección de referencia de plantas psicoactivas, excepto almidones 1) Esclereidas deA. colubrina var. cebil (semilla); 2) Esclereidas de D. inoxia (semilla); 3) Vasos de T. reptans (raíz); 4) Ráfides de P. carthaginensis (hoja); 5) Epidermis de N. tabacum (hoja); 6) Tricomas glandulares con cristales y eglandular de N. tabacum (hoja); 7) Cristales y drusas de D. inoxia (hoja); 8) Cristales y drusas de A. colubrina var cebil (semilla); 9) Aguijones de A. colubrina var. cebil (hoja); 10) Tricoma estrellado de P. carthaginensis (hoja); 11) Tricoma glandular y eglandular de D. inoxia (hoja); 12) Tricomas glandulares y eglandulares de B. arborea (hoja); 13) Epidermis de P. carthaginensis (hoja); 14)

Epidermis de D. inoxia (hoja); 15) Epidermis de C. parqui (hoja); 16) Epidermis de B. arborea (hoja). La escala equivale a $30 \mu \mathrm{m}$.

celulares con cabezuela bicelular en hojas de Cestrum y Nicotiana (Figura 2-6), con cabezuela unicelular en hojas de D. inoxia y de Nicotiana spp. y en hojas y flor de Brugmansia. Con cabezuelas de más células sólo en Nicotiana spp., hoja y flor. Como puede verse, las características de la cabezuela son las más diagnósticas, pero sus escasas posibilidades de preservación en residuos de combustión atentan contra su utilidad en estudios arqueobotánicos. En ningún caso se trata de tricomas silicificados, si bien en el caso de hojas de cebil, los aguijones poseen paredes engrosadas.
Tejidos epidérmicos y estomas. Epidermis de células festoneadas y estomas anisocíticos se encuentran en $C$. parqui (Figura 2-13), siendo característico de esta especie su cutícula estriada, la cual puede potencialmente sufrir alteraciones por combustión. Este tipo de estomas, en epidermis de paredes no tan festoneadas, sino levemente onduladas, se encuentran tanto en B. arborea (Figura 2-16), como en Nicotiana spp. (Figura 2-5). Dentro de estas últimas también puede haber estomas anomocíticos los cuales, en epidermis de paredes festoneadas, se encuentran en D. inoxia (Figura 2-14). Este tipo de estomas 
Protocolos y aVANCes en el estudio de residuos de pipas arqueológicas de Argentina.

APORTES PARA EL ENTENDIMIENTO DE METODOLOGÍAS ACTUALES Y PRÁCTICAS PASADAS

\begin{tabular}{|c|c|c|c|c|c|}
\hline ESPECIE & $\begin{array}{l}\text { ALMIDÓN } \\
\text { TIPO }\end{array}$ & $\begin{array}{c}\text { CARACTERES BAJO LUZ } \\
\text { TRANSMITIDA SIN POLARIZAR }\end{array}$ & $\begin{array}{l}\text { CARACTERES BAJO LUZ } \\
\text { POLARIZADA }\end{array}$ & $\begin{array}{l}\text { PROMEDIO } \\
\quad(\mathrm{mm}) \\
\text { (MAX-MIN) }\end{array}$ & $\begin{array}{c}\mathrm{R} \\
\mathrm{Dma} / \mathrm{Dme} \\
(\mathrm{mm})\end{array}$ \\
\hline \multirow{8}{*}{ N. longiflora } & $\begin{array}{l}\mathrm{A}(\mathrm{N}=10) \\
(\text { Muestras } \mathrm{A}, \mathrm{B} \text { y } \mathrm{C})\end{array}$ & $\begin{array}{l}\text { Grano semicompuesto, elipsoidal }\left(^{*}\right) \\
\text { o elíptico }\left(^{* *}\right) \text { con hilio imperceptible } \\
\text { compuesto por dos gránulos hemisféricos } \\
\left({ }^{*}\right) \text {, truncados }\left(^{* *}\right) \text { o campanuliformes, de } \\
\text { hilio imperceptible o puntiforme céntrico. } \\
\text { Puede tener estriaciones (laminado }{ }^{* *} \text { ) } \\
\text { concéntricas de líneas finas y superficie con } \\
\text { elevaciones }\left(^{*}\right)\end{array}$ & $\begin{array}{l}\text { Birrefringencia moderada a elevada, } \\
\text { líneas de extinción de brazos delgados } \\
\text { y rectos que pueden estar sólo en los } \\
\text { márgenes del grano o formar una cruz } \\
\text { de extinción asimétrica irregular }\left(^{*}\right) \text {, } \\
\text { con forma de "X" o semejante a línea } \\
\mathrm{D}\left({ }^{* *}\right)\end{array}$ & $\begin{array}{c}15,3 \\
(25,9-8,4)\end{array}$ & 1,5 \\
\hline & $\begin{array}{l}\mathrm{B}(\mathrm{N}=3) \\
\text { (Muestras Ay C) }\end{array}$ & $\begin{array}{l}\text { Esférico }\left(^{*}, *^{*}\right) \text { curvado }\left({ }^{*}\right) \text {, hilio } \\
\text { central puntiforme. Puede tener fisuras } \\
\text { leves, lineales, de disposición radial y } \\
\text { ocasionalmente superficie con elevaciones } \\
\left(^{*}\right)\end{array}$ & $\begin{array}{l}\text { Birrefringencia de muy baja a elevada, } \\
\text { cruz de extinción de brazos rectos y } \\
\text { delgados }\end{array}$ & $\begin{aligned} 25,5 \\
(34,1-15,6)\end{aligned}$ & 1,1 \\
\hline & $\begin{array}{l}\mathrm{C}(\mathrm{N}=4) \\
(\text { Muestras } \mathrm{A}, \mathrm{B} \text { y } \mathrm{C})\end{array}$ & $\begin{array}{l}\text { Ovoide }\left(^{*}\right) \text { o trasovado obtuso alargado } \\
\left(*^{*}\right) \text {, hilio elongado }\left(^{*}\right) \text { y hundido o } \\
\text { imperceptible }\end{array}$ & $\begin{array}{l}\text { Birrefringencia moderada a elevada, } \\
\text { cruz de extinción asimétrica }\left(^{*}\right) \text { de } \\
\text { brazos rectos a moderadamente } \\
\text { sinuosos, delgados y proyectados, en } \\
\text { otra vista la cruz posee forma de " } \mathrm{X}\end{array}$ & $\begin{array}{c}14,4 \\
(18,7-10,5)\end{array}$ & 1,1 \\
\hline & $\begin{array}{l}\mathrm{D}(\mathrm{N}=2) \\
\text { (Muestra } \mathrm{B})\end{array}$ & $\begin{array}{l}\text { Esférico }\left(^{*}, *^{*}\right) \text { levemente ovoide }\left({ }^{*}\right) \text {, hilio } \\
\text { imperceptible }\end{array}$ & $\begin{array}{l}\text { Birrefringencia moderada, cruz de } \\
\text { extinción de brazos delgados y rectos } \\
\text { con forma de "X" }\end{array}$ & $\begin{array}{c}8,1 \\
(9,5-6,2)\end{array}$ & 1 \\
\hline & $\begin{array}{l}\mathrm{E}(\mathrm{N}=7) \\
\text { (Muestras By C) }\end{array}$ & $\begin{array}{l}\text { Ovoide }\left(^{*}\right) \text { con una cara plana o truncado } \\
\text { campana alargado }\left(^{(*}\right) \text {, también elipsoidal } \\
\left({ }^{*}\right) \text { o elíptico }\left(^{(*}\right) \text {, menos frecuentemente } \\
\text { elipsoidal recurvado }\left(^{*}\right) \text { o trasovado } \\
\text { comprimido }\left(^{(*}\right) \text {. Hilio imperceptible, } \\
\text { puntiforme, esférico }\left(^{*}\right) \text { o círculo }\left(^{* *}\right) \text {, } \\
\text { excéntrico. Puede tener la zona mesial } \\
\text { levemente hundida, leves estriaciones } \\
\text { concéntricas o fisura central en el hilio }\end{array}$ & $\begin{array}{l}\text { Birrefringencia moderada a elevada, } \\
\text { cruz de extinción asimétrica }\left(^{*}\right) \text { de } \\
\text { brazos finos, rectos o moderadamente } \\
\text { curvos proyectados }\end{array}$ & $\begin{aligned} & 16,9 \\
&(24,5-9,7)\end{aligned}$ & 1,4 \\
\hline & $\begin{array}{l}\mathrm{F}(\mathrm{N}=2) \\
\text { (Muestra B) }\end{array}$ & $\begin{array}{l}\text { Conoide }\left(^{*}\right) \text { trasovado/ oblanceolado }\left(^{* *}\right) \text {, } \\
\text { hilio imperceptible o central filiforme, } \\
\text { elongado }\left(^{*}\right) \text {. La superficie puede tener } \\
\text { elevaciones }\left(^{*}\right)\end{array}$ & $\begin{array}{l}\text { Birrefringencia moderada a elevada, } \\
\text { cruz de extinción de brazos rectos y } \\
\text { delgados, proyectados en el caso de } \\
\text { cruz asimétrica }\end{array}$ & $\begin{array}{c}21,9 \\
(23,7-19,2)\end{array}$ & 1,1 \\
\hline & $\begin{array}{c}\mathrm{G}(\mathrm{N}=3) \\
\text { (Muestra B y } \mathrm{C})\end{array}$ & $\begin{array}{l}\text { Discoidal }\left(^{*}\right) \text { u ovalado }\left(^{* *}\right) \text { hilio } \\
\text { imperceptible. Puede tener estrías } \\
\text { concéntricas tenues, zona mesial hundida, } \\
\text { fisuras lineales }\end{array}$ & $\begin{array}{l}\text { Birrefringencia moderada a elevada, } \\
\text { cruz de extinción con forma de " } \mathrm{X} \text { " de } \\
\text { brazos rectos y delgados }\end{array}$ & $\begin{array}{c}20,5 \\
(24,8-18)\end{array}$ & 1,2 \\
\hline & $\begin{array}{l}\mathrm{H}(\mathrm{N}=2) \\
\text { (Muestra } \mathrm{C})\end{array}$ & $\begin{array}{l}\text { Esférico }\left({ }^{* *}\right) \text {, hilio central puntiforme } \\
\text { fisurado tipo lineal } \mathrm{B}\left({ }^{* *}\right) \text {, con estrías } \\
\text { concéntricas leves }\end{array}$ & $\begin{array}{l}\text { Birrefringencia baja a elevada, cruz de } \\
\text { extinción con brazos rectos gruesos. }\end{array}$ & $\begin{array}{c}16 \\
(21,1-11,6)\end{array}$ & 1 \\
\hline
\end{tabular}

89 \begin{tabular}{l|l}
$N^{\circ} 51 / 2015$ \\
Estudios ATACAMEÑos \\
Arqueología y Antropología Surandinas
\end{tabular} 
Verónica S. Lema, Diego Andreoni, Aylen Capparelli, Gabriela Ortiz, Romina Spano, Marcos Quesada y Flavia Zorzi

\begin{tabular}{|c|c|c|c|c|c|}
\hline \multirow{5}{*}{$\begin{array}{l}\text { A. colubrina } \\
\text { var. cebil. }\end{array}$} & $\begin{array}{c}1 \\
(\mathrm{~N}=12) \\
\text { Muestra } \mathrm{A}, \mathrm{C} ; \mathrm{G}\end{array}$ & $\begin{array}{l}\text { Discoidal }\left(^{*}\right) \text { u ovalado }\left(^{* *}\right) \text {. Zona mesial } \\
\text { con abultamientos haciendo el hilio } \\
\text { imperceptible. Menos frecuentemente: } \\
\text { ovoide }\left(^{(}\right) \text {u ovalado }\left(^{* *}\right) \text {. Puede presentar } \\
\text { estriaciones (laminado }{ }^{* *} \text { ) concéntricas de } \\
\text { líneas finas }\end{array}$ & $\begin{array}{l}\text { Birrefringencia baja, cruz de extinción } \\
\text { con forma de cruz de brazos rectos } \\
\text { y muy anchos o con forma de "X" } \mathrm{y} \\
\text { brazos finos. Los brazos pueden ser } \\
\text { también curvos, delgados en el centro } \\
\text { y anchos en los márgenes }\end{array}$ & $\begin{array}{c}17,7 \\
(28,2-8,4)\end{array}$ & 1,1 \\
\hline & $\begin{array}{c}2 \\
\text { Muestra B, D, E, I }\end{array}$ & $\begin{array}{l}\text { Esférico }\left({ }^{*},{ }^{* *}\right) \text {, hilio central filiforme, } \\
\text { ocasionalmente hundido. Puede tener una } \\
\text { cara plana y ser angular }\left(^{*}\right) \text { o facetado }\end{array}$ & $\begin{array}{l}\text { Birrefringencia moderada a elevada, } \\
\text { cruz de extinción de brazos rectos y } \\
\text { delgados. Ocasionalmente pueden ser } \\
\text { curvos o anchos }\end{array}$ & $\begin{array}{c}3,5 \\
(5,6-2,6)\end{array}$ & 1 \\
\hline & $\begin{array}{c}3 \\
(\mathrm{~N}=5) \\
\text { Muestra A, C,F,H,I }\end{array}$ & $\begin{array}{l}\text { Esférico aplanado }\left(^{*}\right) \text { u ovalado irregular } \\
\text { expandido }\left(^{* *}\right) \text {. Cónico }\left(^{*}\right) \text { o trasovado }\left(^{* *}\right) \\
\text { Ovoide }\left(^{*}\right) \text { con una cara plana o truncado } \\
\text { "campana" alargado }{\left({ }^{* *}\right)}^{\text {Ocasionalmente, superficie con }} \\
\text { protuberancias. } \\
\text { Hilio imperceptible o fisurado-estrellado, } \\
\text { central, hundido. }\end{array}$ & $\begin{array}{l}\text { Birrefringencia baja a moderada } \\
\text { (raramente elevada), cruz de extinción } \\
\text { con forma de "X", de brazos rectos y } \\
\text { delgados, ocasionalmente curvos, o } \\
\text { anchos }\end{array}$ & $\begin{array}{c}17,3 \\
(29,5-8,9)\end{array}$ & 1,2 \\
\hline & $\begin{array}{c}4 \\
(\mathrm{~N}=1) \\
\text { Muestra } \mathrm{E}\end{array}$ & $\begin{array}{l}\text { Elipsoidal }\left(^{(}\right) \text {o elíptico }\left(^{* *}\right) \text {, hilio filiforme } \\
\text { hundido }\end{array}$ & $\begin{array}{l}\text { Birrefringencia baja, líneas de } \\
\text { extinción de tipo } \operatorname{CoD}\left(^{* *}\right)\end{array}$ & $12,5-7$ & 1,8 \\
\hline & $\begin{array}{c}5 \\
(\mathrm{~N}=1) \\
\text { Muestra } \mathrm{H}\end{array}$ & $\begin{array}{l}\text { Poliédrico }\left(^{*}\right) \text { o pentagonal agudo recto } \\
\left({ }^{*}\right) \text {, hilio central puntiforme }\end{array}$ & $\begin{array}{l}\text { Birrefringencia baja, cruz de extinción } \\
\text { de brazos rectos }\end{array}$ & $19,5-15,4$ & 1,3 \\
\hline \multirow{4}{*}{ T. reptans } & $\begin{array}{c}\mathrm{I} \\
(\mathrm{N}=3)\end{array}$ & $\begin{array}{l}\text { Esférico }\left({ }^{*},{ }^{*}\right) \text {, puede tener una cara plana. } \\
\text { Hilio filiforme o fisurado asimétrico radial } \\
\left(^{* *}\right) \text { central a levemente excéntrico }\end{array}$ & $\begin{array}{l}\text { Birrefringencia moderada a elevada, } \\
\text { cruz de extinción con forma de "X", } \\
\text { con brazos delgados, curvos o rectos }\end{array}$ & $\begin{array}{c}18,3 \\
(25,2-9,9)\end{array}$ & 1,1 \\
\hline & $\begin{array}{c}\text { II } \\
(\mathrm{N}=2)\end{array}$ & $\begin{array}{l}\text { Elipsoidal }\left(^{*}\right) \text { o elíptico }\left(^{* *}\right) \text {, o bien, ovoide } \\
\left({ }^{*}\right) \text { o trasovado obtuso alargado }\left(^{* *}\right) \text {. Hilio } \\
\text { imperceptible, central }\end{array}$ & $\begin{array}{l}\text { Birrefringencia moderada a elevada, } \\
\text { cruz de extinción de brazos rectos y } \\
\text { delgados }\end{array}$ & $\begin{array}{c}16 \\
(19,5-11)\end{array}$ & 1,8 y 1,2 \\
\hline & III $(\mathrm{N}=1)$ & $\begin{array}{l}\text { Hemisférico }\left(^{*}\right) \text { o truncado }\left(^{* *}\right) \text { Superficie } \\
\text { levemente irregular. Hilio central, elongado } \\
\left(^{*}\right)\end{array}$ & $\begin{array}{l}\text { Birrefringencia elevada, línea } \mathrm{E}\left({ }^{* *}\right) \text { de } \\
\text { extinción de brazos rectos y delgados }\end{array}$ & $27,9-22$ & 1,3 \\
\hline & $\operatorname{IV}(\mathrm{N}=1)$ & $\begin{array}{l}\text { Cónico }\left(^{*}\right) \text { o trasovado obtuso }\left(^{* *}\right) \text {, hilio } \\
\left.\text { fisurado (forma "Y" }{ }^{* *}\right) \text {, excéntrico, } \\
\text { hundido }\end{array}$ & $\begin{array}{l}\text { Birrefringencia elevada, cruz de } \\
\text { extinción asimétrica }\left(^{*}\right) \text {, con brazos } \\
\text { rectos proyectados }\end{array}$ & $14,3-11,4$ & 1,3 \\
\hline
\end{tabular}

Tabla 2. Clasificación y caracterización cuantitativa y cualitativa de almidones de referencia.

Nota general: N: cantidad de almidones registrados por tipo; Promedio: de todas las medidas (dos por grano o granula), MAX: valor máximo registrado, MIN: valor mínimo registrado; R Dma/Dme: relación diámetro mayor/diámetro menor (se coloca el número más frecuente). Se emplearon diferentes descriptores: $\left(^{*}\right)=\mathrm{IC}_{5} \mathrm{~N} ;\left(^{* *}\right)=$ Pagan Jiménez (2011) y se combinan ambos sistemas de clasificación, cuando los términos son diferentes pero se consideran equivalentes se colocan intermediados por una "o"; cuando se usa un término de un sistema de nomenclatura como complementario o modificador de un término del otro sistema no se coloca "o". La ausencia de asteriscos señala nuestros propios términos. N. longiflora: muestras A, B y C refieren a distintos montajes de un mismo preparado de raíz colectada en la ciudad de La Plata (Buenos Aires) en 2012. A. colubrina var. cebil.: muestras A,E,F,G y H procedentes del Parque Nacional Las Lancitas (Jujuy); B, C y D de colecciones LEBA área NOA; I corresponde a ejemplares adquiridos en 2013, Manca Fiesta, La Quiaca (Jujuy). Procesamiento de las muestras: A: cotiledones frescos en agua destilada; B: semillas tostadas, molidas y quemadas en tubo de ensayo; C: raspado directo sobre cotiledones frescos; D: cotiledones frescos centrifugados (10oo rpm, 4 minutos); E: corte transversal de semilla; F a I: cotiledones frescos en agua destilada. T. reptans: muestra del Herbario MLP procedente de Pampa Grande (Salta). 
Protocolos y aVANCES EN El ESTUdio de Residuos de pipas arqueológicas de Argentina.

APORTES PARA EL ENTENDIMIENTO DE METODOLOGÍAS ACTUALES Y PRÁCTICAS PASADAS



Figura 3. Colección de referencia de plantas psicoactivas, almidones 1) Tipo A de N. longiflora; 2) Tipo II de T. reptans; 3) Tipo E de N. longiflora; 4) Tipo 3 de A. colubrina var. cebil; 5) Tipo C de N. longiflora; 6) Tipo I de A. colubrina var. cebil; 7) Tipo F de N. longiflora;

8) Tipo IV de T. reptans. La escala equivale a $50 \mu \mathrm{m}$.

se halla también en las hojas de cebil, pero en este caso la epidermis está constituida por células subcuadrangulares o subrectangulares, moderadamente onduladas. P. carthaginensis posee la más distintiva de las epidermis foliares con células poligonales de paredes rectas y estomas paracíticos y actinocíticos; si bien el mesófilo posee células de contorno festoneado, éstas exhiben paredes notablemente más delgadas que las de aquellas de igual morfología en epidermis de los otros taxa (Figura 2-13). Como puede apreciarse, salvo en este último caso, se requiere de la recuperación de una porción de tejido que posea, al menos, un estoma y algunas células epidérmicas en conexión orgánica para poder proponer una identificación taxonómica.

Almidones. En el caso de N. longiflora, el tipo A (Figura 3-1) resultó el más frecuente (30,3\% de la muestra) y el más diagnóstico. En el caso del cebil, el tipo i (Figura 3-6) resulta uno de los más abundantes ( $48 \%$ de la muestra), a lo cual se suma su alto valor diagnóstico.

Los almidones esféricos resultan los más ubicuos y menos diagnósticos, estando presentes en todos los casos, con diferencias de tamaño. El cebil posee los almidones esféricos más pequeños, siendo el único tipo que sobrevivió al procesamiento y combustión de las semillas (Tabla 
2). Entre los tipos elipsoidales, el tipo E de $N$. longiflora y el 4 de cebil (Figura 3-3) resultan característicos. En el caso de los ovoides, el tipo II de T. reptans (Figura 3-2) y el $\mathrm{C}$ de N. longiflora (Figura 3-5) coinciden en sus caracteres cuali y cuantitativos. El tipo cónico o trasovado posee diferencias principalmente cuantitativas entre el tipo 3 de cebil (Figura 3-4) y el IV de T. reptans (Figura 3-8), estando el rango de tamaño de este último incluido en el del primero, al igual que el tipo conoide (F) de N. longiflora (Figura 3-7).

\section{Identificación de micro-restos de los residuos ar- queológicos an alizados}

En lo que refiere a almidones (Tabla 1), los tipos más frecuentes fueron el 1 de cebil (Figura 4: 1-4, 8-9) y los tipos C de N. longiflora o II de T. reptans (Figura 4: 14-15, 17-18, 22-23). La presencia de $N$. longiflora pudo constatarse en muestras donde se halló el tipo $\mathrm{A}$, de carácter diagnóstico. Las identificaciones taxonómicas realizadas a partir de los tipos 3 (cebil), F (N. longiflora) e I (T. reptans), que no



Figura 4. Micro-restos recuperados de pipas arqueológicas. 1) Almidón tipo 1 de cebil, La Candelaria; 2) Almidón tipo 1 de cebil, Arroyo Colorado; 3) Ídem anterior, polarizado; 4) Almidón tipo I de cebil, Huachichocana III, pipa 2038; 5) Almidón tipo C Nicotiana/tipo II Trichocline, base cerámica El Taco 19; 6) Ídem anterior, polarizado; 7) Almidón de Triticum spp., Bolívar 373, pipa 3; 8) Almidón tipo 1 de cebil, Fraile Pintado; 9) Ídem anterior, polarizado; 10) Aguijón, Soria 2; 11) Almidón tipo C Nicotiana/tipo II Trichocline, base cerámica El Taco 19; 12) Ídem anterior, polarizado; 13) Cabezuela glandular de tricoma, Bolivar 373, pipa 4; 14) Almidón tipo C Nicotiana/tipo II Trichocline, Fraile Pintado; 15) Ídem anterior, polarizado; 16) Esclereida, pipa El Taco 19; 17) Almidón tipo C Nicotiana/tipo II Trichocline, Arroyo Colorado; 18) Ídem anterior, polarizado; 19) Fragmento de tejido epidérmico, Bolivar 373, pipa 3; 20) Fragmento de tricoma, Bolivar 373 , pipa 4; 21) Cristal cúbico, Soria 2; 22) Almidón tipo C Nicotiana/tipo II Trichocline, pipa El Taco 19; 23) Ídem anterior, polarizado; 24) Tricoma estrellado/ramificado, Arroyo Colorado; 25) Elemento de vaso con engrosamiento escalariforme, La Candelaria; 26) Tricoma estrellado/ramificado, La Candelaria; 27) Elemento de vaso, Fraile Pintado; 28) Polen, La Candelaria; 29) Vasos con engrosamiento espiralado, Fraile Pintado; 30 ) Elemento de vaso, Arroyo Colorado. La escala equivale a $30 \mu \mathrm{m}$. 
poseen carácter diagnóstico, se realizaron por sumatoria de rasgos (tamaño, hilio, entre otros) presentes en los almidones arqueológicos que los acercan a cada tipo y los alejan de especímenes similares hallados en otros taxa. En casos como estos, el consumo de dichas especies debe ser confirmado por otros tipos de restos, o quedar en un plano hipotético. A las muestras presentadas en la Tabla 1 se sumó el análisis de una base de recipiente cerámico del sitio El Taco 19, hallada en el mismo recinto que la pipa, ya que en ella se recuperaron los mismos tipos de almidones que resultaron frecuentes en las pipas (tipo 1 de cebil y tipos C de N. longiflora/II de T. reptans (Figura 4: 5-6, 11-12). En este caso, sin embargo, el carácter diagnóstico de los almidones hasta aquí caracterizados se relativiza, puesto que hay que considerar sus rasgos en función de otro set de plantas que incluyen alimenticias, entre otras. A pesar de esto, los tipos de almidones identificados en esta base no coinciden con otros registrados en nuestras colecciones de referencia más generales de micro-restos. La única excepción son los almidones hemisféricos de tipo A de Nicotiana, semejantes a los de Oxalis famatinae, especie actualmente presente en los alrededores del sitio, por lo cual la adscripción taxonómica de este tipo de almidones requiere de mayores trabajos a futuro.

Las fibras suelen ser frecuentes en los residuos de pipas $y$, en aquellos casos en que hemos podido determinarlas (Soria 2, Campo Colorado, Arroyo Colorado, Fraile Pintado, El Taco 19), correspondieron a algodón y lo vinculamos a actividades de limpieza o a la colocación de tapones que actúan a modo de filtros. Las características de algunas de las restantes fibras halladas indican que las mismas sean posiblemente liberianas o floemáticas, por lo cual su caracterización será una tarea a desarrollar a futuro, sobre todo en tallos y raíces. En el caso de las pipas de colecciones, existe la posibilidad de que las fibras recuperadas en los residuos procedan de elementos con los que tuvieron contacto las pipas antes de llegar al laboratorio de arqueobotánica (papel, guantes de tela, etc.). A pesar de ello, creemos que el hecho de que las fibras formen parte de un conjunto donde hay restos de plantas con propiedades psicoactivas - al igual que la presencia de estas fibras en piezas cuya trayectoria desde el campo al laboratorio, se sabe, fue cuidada para evitar contaminación (p.e., Soria 2) - permite considerar la posibilidad de que los restos de algodón estén vinculados a las actividades fumitorias pasadas. En cuanto a las esclereidas, las que se han recuperado de las distintas pipas (Tabla 1, Figura 4-16) no coinciden con las de referencia, ni poseen similitud entre sí.

Fragmentos de haces vasculares con engrosamiento espiralado fueron recuperados en numerosas pipas (Tabla 1, Figura 4-29); lamentablemente éstos no son diagnósticos. En cuanto a los vasos (Tabla 1, Figura 4-25 y 4-27), algunos resultaron diagnósticos, como los recuperados en la pipa del sitio Arroyo Colorado, que se corresponden con los de rizomas de T. reptans (Figura 4-30). Si bien escasos, pudieron recuperarse fragmentos de tejidos. En algunos casos, las características de las células epidérmicas y los estomas indican grandes grupos o familias. Por ejemplo, la muestra de tejido de la pipa 2037 de CHIII parecería corresponder a una gramínea. Esto es coincidente con los resultados obtenidos en el análisis de pipas arqueológicas recuperadas en Chile, donde los fitolitos señalan también la presencia de restos de esta familia, posiblemente vinculado a su uso como yesca (Quiroz et al. 2012). El hallazgo concuerda también con una célula aislada recuperada en el residuo de una de pipa de Campo Colorado, cuya morfología sugiere que se trata de una célula buliforme, presente en monocotiledóneas. En algunos casos, el fragmento de tejido no posee caracteres diagnósticos de taxa, pudiendo establecerse solamente que se trata de un parénquima o de una epidermis ( $\mathrm{Fi}-$ gura 4-19). En la base del recipiente cerámico de El Taco 19, se recuperó un fragmento de tejido esclerenquimático que coincide en sus caracteres cualitativos con los de raíz de $N$. longiflora, si bien en esta última muestra el tamaño de las células es menor a aquel registrado en el residuo arqueológico. Al igual que en el caso de los almidones, estas diferencias de tamaño pueden deberse a variaciones específicas o subespecíficas, a condiciones de crecimiento donde inciden factores naturales y/o culturales, o bien a distintos estadios del desarrollo de un mismo taxa. También se recuperaron tricomas o partes de los mismos en varios ejemplares. En el caso de los aguijones recuperados en la pipa de Soria 2 (Figura 4-10) y en la pipa 2037 de CHIII, los mismos son similares a los registrados en los foliolos de cebil. En otros casos, se han encontrado células de paredes delgadas cuya morfología remite a cabezuelas glandulares, tales como las que se encuentran en pelos glandulares de hojas de tabaco (Figura 4-13). También la asociación de células entre sí (Figura 4-20) ha permitido sugerir la presencia de un tricoma uniseriado, 
al menos bicelular, sin que pueda descartarse que sea un pie de tricoma glandular. Finalmente, tricomas estrellados/ramificados se han encontrado sólo en dos pipas: La Candelaria (Figura 4-26) y Arroyo Colorado (Figura 4-24). Si bien no podemos asegurar su identificación, nos inclinamos por Cestrum spp. ya que posee tricomas semejantes. Por último, mencionamos la presencia de un grano de polen (Figura 4-28) en la pipa de la colección Schreiter. Llamativamente, el polen fue menos frecuente de lo esperado en las muestras, siendo este el único caso donde se lo registró. Si bien este elemento pudo sumarse al material consumido de manera incidental, tampoco puede descartarse a priori el consumo fumitorio de flores, el cual queda como hipótesis a investigar. En cuanto a los cristales, los cúbicos y poliédricos son conspicuos en las muestras de referencia, y en términos generales en otras especies, por lo cual su presencia en algunos residuos (Figura 4-21) no permite precisar taxa ni órgano.

En el caso del conjunto de pipas del sitio Bolívar 373, si bien en la pipa 3 se hallaron almidones (con y sin daño) de trigo ${ }^{10}$ (Figura 4-7), tanto en ésta como en la pipa 6 y 7 algunos almidones podrían corresponderse al tipo 1 de cebil, el cual resulta similar. En el caso de contextos históricos, se debe profundizar el estudio de rasgos que permitan diferenciar almidones de una y otra especie para ser conclusivos al respecto. Las restantes estructuras recuperadas (p.e., partes de tricomas, tejidos de conducción) sugieren la presencia de hojas completas empleadas como fumitorio, probablemente tabaco considerando el contexto histórico del sitio. En el caso de Soria 2 y Campo Colorado los restos no son resolutivos acerca de los vegetales fumados, lo cual se condice con los resultados negativos de las cromatografías. En la muestra de Tebenquiche se obtuvieron muy pocos restos, los que señalan el consumo de hojas. Caso contrario fue La Candelaria, donde los almidones indican la presencia de cebil y raíz/ rizoma de Nicotiana/Trichocline; la presencia de vasos

10 Cabe mencionar la recuperación de granos de Zea mays en una pipa de Soria 2 (Andreoni et al. 2012). Si bien en la preparación de A. peregrina como inhalatorio se incluyen harinas (Pagan Jiménez y Carlson 2014), también cabe la posibilidad de que el acto de fumar se realizara en contextos donde se estaban procesando harinas, las cuales, por ser altamente volátiles, pudieron incidentalmente incorporarse al residuo de pipas. Este aspecto queda aún en un plano hipotético y requiere de mayores estudios. sugiere también la presencia de raíz, rizoma y/o tallo; el tricoma, hojas posiblemente de Cestrum y el polen, flores quizá. En cuanto a las pipas San Francisco, en ambos casos se detectaron fibras afines a algodón, almidones de cebil, de raíz de $N$. longiflora y de $N$. longiflora/T. reptans. En el caso de Arroyo Colorado, el consumo de Trichocline quedaría afirmado por la presencia de un elemento de vaso. La presencia de otros tipos de vasos también apoya el consumo de raíces/rizomas/tallos. Un tricoma indica el consumo fumitorio de hojas y/o tallos verdes. En Fraile Pintado se recuperaron vasos y fibras cuyos caracteres remiten también a raíces/rizomas/tallos. En el caso de ambas pipas de Huachichocana, los almidones indican la presencia de raíces de N. longiflora, rizomas de T. reptans y semillas de cebil. De la pipa de El Taco 19 se recuperaron restos asignables a raíz/rizoma de $N$. longiflora/T. reptans (al igual que en la base cerámica), vasos asignables a este tipo de órganos y fibras de algodón. En un solo caso hay un almidón similar a los de tipo 1 de cebil. La presencia de esta especie estaría apoyada por el análisis del contenido de una valva de caracol de gran tamaño, también recuperada en El Taco 19, que proporcionó micro-restos afines a cebil y Nicotiana (Martin 2011).

\section{* Consideraciones Finales}

A lo largo de este trabajo hemos podido examinar el tratamiento de residuos de combustión de pipas arqueológicas procedentes de sitios que difieren desde lo cronológico y lo geográfico, elaboradas en distintos soportes, con estados de conservación disímiles, halladas en contextos domésticos o funerarios y conteniendo residuos diversos (costras, tiznado). Se analizaron ejemplares recuperados en excavaciones arqueológicas por investigadores que se interesaron por el análisis de su contenido, otros que forman parte de colecciones de museo y, finalmente, algunos recuperados por particulares y que forman parte de colecciones privadas. No deja de ser estimulante encontrar datos de interés en piezas de colecciones, pudiendo resignificarse este patrimonio empleando los recursos que nos provee la disciplina en la actualidad. Contamos con un panorama amplio de situaciones analizadas, todas las cuales han dado resultados positivos a través de técnicas de recuperación de residuos, procesamiento de los mismos y montaje para su observación en laboratorio, que demostraron ser apropiadas. Una colección de referencia amplia a nivel taxonómico, con variedad de 
órganos representados por cada taxa y con muestras con y sin procesamiento de partes vegetales, resultó esencial. Tomando en cuenta todo ello, discutiremos brevemente aspectos que consideramos de interés.

En cuanto a los tratamientos químicos, los mismos resultaron adecuados para recuperar una gran diversidad de tipos de micro-restos, sin que hayamos detectado casos donde el tratamiento destruyera por completo el material orgánico. En el caso de micro-restos no identificados, los mismos no sólo no coinciden con lo observado en ejemplares actuales o con lo mencionado en la bibliografía, sino que tampoco son similares entre sí. La ausencia de redundancia de formas sugiere que no hubo un uso intensivo de un mismo órgano de un taxa, sino que se habrían empleado diversas partes de plantas, posiblemente de diferentes especies. Esto coincide con lo indicado en fuentes escritas, las cuales dan cuenta del consumo como fumitorios de un importante número de taxa, así como de diversas partes de plantas. En este sentido, podemos mencionar al cebil, el cual suele ser detectado mediante cromatografías gaseosas como única planta consumida ${ }^{11}$, si bien en los registros etnográficos suele estar acompañado, al menos, por tabaco (Andreoni y Capparelli 2007). En algunos casos, el escaso poder resolutivo de una estructura se apoya en el carácter diagnóstico de otra, habilitando la interpretación del residuo como un todo. Corroborar o no las identificaciones propuestas en este trabajo será función de la ampliación de la colección de referencia a futuro. Al momento, contamos con gran número de elementos y de taxa reconocidos en un mismo residuo, aunque no podemos asegurar aún si estamos ante una particular combinatoria de plantas o sus partes (una "receta" peculiar), o ante la sumatoria de residuos de usos de plantas a lo largo del tiempo.

La ausencia de elementos con altas probabilidades de conservación en los residuos, como es el caso de las macroesclereidas de las cubiertas seminales de cebil, llama la atención, máxime considerando su presencia en residuos de tubos de inhalación del noroeste argentino (Pochettino et al. 1999). Las experimentaciones realizadas por Pagan Jiménez y Carlson (2014) señalan la buena conservación de elementos de la testa versus la escasa preservación de almidones por el proceso de tostado. Considerando esto, junto con nuestras experimentaciones y los resultados obtenidos en las pipas, proponemos la posibilidad de que se incluyeran semillas sin testa como material fumitorio en el pasado.

El análisis de una base de recipiente cerámico nos permitió abrir la mirada analítica al considerar la presencia de plantas con propiedades psicoactivas por fuera de pipas y elementos vinculados al llamado "complejo del rapé" (tabletas, tubos, inhaladores). Esto puede representar tanto la intervención de objetos diversos en las cadenas de procesamiento de vegetales a ser consumidos mediante el uso de los implementos antes citados, o bien, ser el soporte material para el consumo líquido de este tipo de plantas. Esto último es coherente con referencias históricas acerca del consumo de bebidas (p.e. chicha) donde eran incluidas plantas como el coro o el cebil (Pérez Gollan y Gordillo 1993).

Esperamos que la realización de un número mayor de tareas de investigación vinculadas a las prácticas fumitorias pasadas nos permita avanzar y consolidar nuestros conocimientos acerca de estas prácticas en sus distintos contextos espaciotemporales.

Agradecimientos A los evaluadores, quienes con su atenta lectura ayudaron a mejorar versiones previas de este artículo. A los colegas con quienes hemos intercambiado perspectivas acerca del análisis de pipas en diferentes y fructíferos encuentros académicos a lo largo de los últimos años.

11 Tomamos esto en términos generales, si bien en muchos casos se asume la presencia de dimetiltriptamina (DMT) como diagnóstico de cebil, cuando el elemento que es exclusivo de esta especie es la bufotenina o 5-methoxy-N, N-dimetiltriptamina. 


\section{* Referencias citadas}

ALBORNOZ, X. 2015. Colección de referencia de elementos histológicos para estudios de micro-restos vegetales: especies psicoactivas y aromáticas de los Andes Centro-Sur. En Avances y desafíos metodológicos en arqueobotánica: miradas consensuadas y diálogos compartidos desde Sudamérica, C. Belmar y V. Lema. (Eds.), pp. 497-516. Universidad SEK, Santiago de Chile.

ANDREONI, D. 2010. Propuesta metodológica para reconocer las prácticas asociadas al uso de pipas arqueológicas. En Arqueología Argentina en el Bicentenario de la Revolución de Mayo. Actas del XVII Congreso Nacional de Arqueología Argentina, 3, J. R. Bárcena y H. Chiavazza (Eds.), pp. 1212-1216. Universidad Nacional de Cuyo, Mendoza.

ANDREONI, D., R. SPANO y V. LEMA. 2012. Nota sobre evidencias de uso de plantas en el sitio Soria 2 a partir del análisis microscópico del contenido de pipas. Arqueología 18: 235-243.

ANDREONI, D. y A. CAPPARELLI. 2007. Compilation of plants involved in the use of South American pipes: a contribution to archaeobotanical contrast. En Programme and Abstracts of the 14th Symposium of the International Work Group for Palaeoethnobotany, A. Bieniek (Ed.), pp 105. , W. Szafer Institute of Botany, Polish Academy of Sciences, Kraków.

BABOT, M. P. 2007. Granos de almidón en contextos arqueológicos: posibilidades y perspectivas a partir de casos del Noroeste argentino. En Paleoetnobotánica del cono sur: Estudios de caso y propuestas metodológicas, B. Marconetto, P. Babot y N. Oliszewski (Comps.), pp: 95-125. Ed. Ferreira, Córdoba.

2009. La cocina, el taller y el ritual: explorando las trayectorias del procesamiento vegetal en el noroeste argentino. Darwiniana $47(1): 7-30$.

BELMAR, C., L. QUIROZ, H. NIEMEYER, M. PLANELlA, X. ALBORNOZ, F. MENESES, S. ALFARO, C. CARRASCO, K. COLLAO-ALVARADO y J. ECHEVERRIA. 2015. Condiciones previas para el uso de marcadores arqueobotánicos y químicos en estudios arqueológicos sobre Complejos Fumatorios: una propuesta de protocolo para manipulación del objeto y toma de muestras. Intersecciones en Antropología 15: 497-501.

CAPPARELLI, A., M. POCHETTINO, D. ANDREONI y R. ITURRIZA. 2006. Difference between written and archaeological record: The case of plant micro remains recovered at a Norhwestern Argentinean Pipe. En Proceedings of the IV International Congress of Ethnobotany, Z. Füsun Ertug (Ed.), pp: 397-406. Yeditepe University, Estambul.
CARPANO, S., E. SPEGAZZINI y M. NAJERA. 1990. Parámetros para la caracterización micrográfica de Solanaceae empleadas en infusiones o fumatorios psicoactivos. Acta Farm. Bonaerense 9(2): 101-109.

CHASE SARDI, M. 1977. El uso Mágico-Religioso y Medicinal de algunas Solanaceas en la Cultura Nivaklé. En Proceedings of the Simposio Internazionale sulla Medicina Indígena e Popolare dell'America Latina, pp 191-209. Instituto Italo-Latinoamericano, Roma.

FERNÁNDEZ DISTEL, A. 1980. Hallazgo de pipas en complejo precerámico del borde de puna Jujeña (República Argentina) y el empleo de alucinógenos por parte de la misma cultura. Estudios Arqueológicos 5: 55-75.

GARCÍA-TEJEDA, Y., P. ZAMUDIO-FLORES, L. BELLO-PÉREZ, C. ROMERO-BASTIDA y J. SOLORZA-FERIA. 2011. Oxidación del almidón nativo de plátano para su uso potencial en la fabricación de materiales de empaque biodegradadables: caracterización física, química y morfológica. Revista Iberoamericana de polímeros 12(3): 125-135.

GOODSPEED, T. 1954. The genus Nicotiana. Chronica Botanica Company, Massachusetts.

HENRY, A., H. HUDSON y D. PIPERNO. 2009. Changes in starch grain morphologies from cooking. Journal of Archaeological Science 36: 915-922.

ICSN. 2011. The International Code for Starch Nomenclature, http:// www.fossilfarm.org/ICSN/Code.html. Consultado: abril 2014.

KORSTANJE, M. A. y M. P BABOT. 2005. A microfossil characterization from South Andean economic plants. En Pleaces, people and plants: using phytoliths in Archaeology and Palaeoecology. Proceedings of the $4^{\text {th }}$ International Meeting on Phytolith Research, M. Madella, M. K. Jones y D. Zurro (Eds.), pp: 41-72. Oxbow Books, Cambridge.

KRAPOVICKAS, P. 1955. Elyacimiento de Tebenquiche. Publicaciones del Instituto de Arqueología, Facultad de Filosofía y Letras, Universidad de Buenos Aires, Buenos Aires.

LISCOVSKY, I. y M. COSA. 2005. Anatomía comparativa de hoja y tallo en los representantes de Cestreae G. Don (Solanaceae) de Argentina. Gayana Botanica 62(1): 33-43.

MARTIN, V. 2011. Informe Final Becas EVC - CIN. Convocatoria 2011. Ms. 
ORTIZ, G. y L. NIEVA. 2014. Morir en el valle de San Francisco. Practicas funerarias, termoalteración y estrategias de memorización en la selva pedemontana de las yungas del NOA. Zeitschrift für Archäologie Außereuropäischer Kulturen $N^{\circ}$ 6, Bonn. Alemania (en prensa).

ORTIZ, G. y C. HEIT. 2011. Determinación de uso de enteógenos en pipas arqueológicas tempranas a través del análisis de ácidos grasos. Trabajo presentado en el III Congreso Latinoamericano de Arqueometría, Arica. Ms.

PAGAN JIMÉNEZ, J. 2011. Useful plants identifiedthrough ancient starch grainsrecovered from ceramic an lithic artefacts, the Chemin Saint Louis site, French Guinea. En Chemin Saint Louis, M. van den Bel (Ed.), pp. 400-469. Institut National de recherches archeologiques preventives, Bègles.

PAGAN JIMÉNEZ, J. y L. CARLSON. 2014. Recent archaeobotanical findings of the hallucinogenic snuff cojoba (Anadenanthera peregrina (L.) Speg.) in precolonial Puerto Rico. Latin American Antiquity 25(1): 101-116.

PALAMARCZUK, V., R. SPANO, F. WEBER, D. MAGNIFICO, S. LÓPEZ y M. MANASIEWICZ. 2007. Soria 2. Apuntes sobre un sitio Formativo en el Valle de Yocavil (Catamarca, Argentina). Intersecciones en Antropología 8: 121-134.

PÉREZ GOLLÁN, A. e I. GORDILLO. 1993. Alucinógenos y sociedades indígenas del Noroeste argentino. Anales de Antropología 30: $299-350$.

PLANELLA, M., C. BELMAR, L. QUIROZ y D. ESTÉVEZ. 2012. Propuesta integradora para un estudio del uso de plantas con propiedades psicoactivas en pipas del período alfarero temprano y sus implicancias sociales. Revista de Antropología 25(1): 93-119.

POCHETTINO, M., A. CORTELLA y M. RUIZ. 1999. Hallucinogenic snuff from Northwestern Argentina: microscopical identification of Anadenanthera columbrina var. cebil (Fabaceae) in powdered archaeological material. Economic Botany 53(2): 127-132.

QUESADA, M., M. GASTALDI y G. GRANIZO. 2012. Construcción de periferias y producción de lo local en las cumbres de El Alto-Ancasti. Relaciones de la Sociedad Argentina de Antropología 37(2): 435-456.

QUIROZ, L., C. BELMAR, M. PLANELLA, R. MERA y D. MUNITA. 2012. Estudio de microfósiles de residuos adheridos en pipas cerámicas del sitio Villa JMC-1 Labranza, región de la Araucanía. Magallania 40(1): 249-261.
QUIROZ, L., C. BELMAR, M. PLANELLA, H. NIEMEYER, X. ALBORNOZ y F. MENESES. 2015. Colección de referencia de microrrestos de las especies nativas del género Nicotiana en Chile. En Avances y desafíos metodológicos en arqueobotánica: miradas consensuadas y diálogos compartidos desde Sudamérica, C. Belmar y V. Lema (Eds.), pp: 517-531. Universidad SEK, Santiago de Chile.

RADLEY J. 1968. Starch and its derivatives. Editorial Chapman and Hall, Londres.

RIVAS-GONZÁLEZ M., M. MÉNDEZ-MONTEALVO, M. SÁNCHEZ-RIVERA, M. NÚÑEZ-SANTIAGO y L. BELLOPÉREZ. 2008. Caracterización morfológica, molecular y fisicoquímica del almidón de plátano oxidado y lintnerizado. Agrociencia 42: 487-497.

ROSSO, C. y R. SPANO. 2005-2006. Humo del vecino: evidencia del uso de alucinógenos en pipas halladas en dos sitios tempranos de los valles calchaquíes. Revista Arqueología 13: 79-98.

SCARPA, G. y C. ROSSO. 2011. Etnobotánica del "coro" (Nicotiana paa, Solanaceae): un tabaco silvestre poco conocido del extremo sur de Sudamérica. Bonplandia 20(2):391-404.

TAKAHASHI, T., Y. TSUCHIDA y M. IRIE. 1982. Isolation of two inactive fragments of a Rhizopus sp. glucoamylase: relationship among three forms of the enzyme and the isolated fragments. Journal of Biochemistry 92: 1623-1633.

TARRAGÓ, M. 1980. Asentamientos aldeanos tempranos en el sector septentrional del valle Calchaquí, provincia de Salta y el desarrollo agrícola posterior. Estudios Arqueológicos 5: 29-53.

WANDSNIDER, L. 1997. The roasted and the boiled: food composition and heat treatment with special emphasis on pit-hearth cooking. Journal of anthropological archaeology 16: 1-48.

ZARDINI, E. 1976-1977. The identification of an Argentinian Narcotic. Botanical Museum Leaflets 25(3): 105-107.

ZARRILLO, S., D. PEARSALL, J. RAYMOND, M. TISDALE y D. QUON. 2008. Directly dated starch residues document early formative maize (Zea mays L.) in tropical Ecuador. PNAS $105(3)$ : 5006-5011.

ZORZI, F. y P. DAVEY. 2011. Descripción del conjunto de pipas halladas en el sitio Bolívar 373. En Temas y problemas de la Arqueología Histórica, M. Ramos, A. Tapia, F. Bognanni, M. Fernández, V. Helfer, C. Landa, M. Lanza, E. Montanari, E. Néspolo y V. Pineau (Eds.), pp: 203-213. Universidad Nacional de Luján, Buenos Aires. 